Bol. Acad. peru. leng. 50. 2010 (83-128)

\title{
LA LENGUA PESCADORA
}

\section{LA LANGUE PÊCHEUSE}

\section{THE LANGUAGE PESCADORA}

\author{
José Antonio Salas García
}

Resumen:

El presente artículo versa sobre nuevos hallazgos con respecto a una entidad idiomática que fue conocida, durante la época colonial, como lengua pescadora. Nuevas noticias acerca de este extinto idioma nos permiten no solamente ampliar el conocimiento que se tenía, sino que nos facultan para reinterpretar asunciones hechas sin suficiente apoyo empírico. El trabajo se beneficia de la publicación de nuevos documentos que, correctamente interpretados, proporcionan luces que iluminan el panorama lingüístico de la costa norperuana. La exposición de los datos, además, está acompañada de mapas que facilitan la comprensión del texto y hacen más agradable su lectura.

Résumé:

Le présent article porte sur les nouvelles découvertes en ce qui concerne un organisme idiomatique, connue pendant l'époque coloniale comme langue pêcheuse. Les dernières nouvelles à propos de cette langue éteinte nous permettent non seulement d'agrandir la connaissance qui existait, mais ils nous autorisent pour réinterpréter des assomptions faites sans 
avoir l'appui empirique suffisant. Le travail bénéficie de la publication de nouveaux documents lesquels correctement interprétés, proportionnent les lumières qui illuminent le panorama linguistique de la côte nord- péruvienne. De plus, l'exposition des données est accompagnée des cartes qui facilitent la compréhension du texte et font sa lecture plus agréable.

\section{Abstract:}

The following article turns on new findings regarding an idiomatic entity that was known during the colonial period as pescadora language. Latest news about this extinct language allow us not only to extend the knowledge that they had, but they let us to reinterpret assumptions done without enough empirical support. The work benefits from the publication of new documents that, correctly interpreted, provide lights that illuminate the linguistic panorama of the northeren coast. The exhibition of the information, moreover, is accompanied of maps that makes the comprehension of the text easier and its reading more pleasant.

\section{Palabras clave:}

Lengua pescadora; idiomas de la costa norperuana; lingüística histórica.

Mots clés:

Langue pêcheuse; langues de la côte nord-péruvienne; linguistique historique.

Key words:

Pescadora Language; languages in northeren coast; historical linguistics.

Fecha de recepción:

$01 / 08 / 2010$

Fecha de aceptación:

$30 / 09 / 2010$

0. Se conoce con el nombre de lengua pescadora a una entidad lingüística que se habría hablado en la costa del Pacífico boreal peruano. De ella sólo se cuenta con las menciones de su existencia en los documentos 
de la época colonial correspondientes al arzobispo Toribio de Mogrovejo (1593 y $1605^{1}$ ), al cronista dominico Reginaldo de Lizárraga (1605), al gramático Alonso de Huerta (1616), al anónimo documento Ramos (1630), al notario Andrés de Obregón $(1631)^{2}$ y, finalmente, al cronista agustino Antonio de la Calancha (1639). Además de estos autores es de fundamental importancia la información que proporciona Fernando de la Carrera (1644), porque da una idea detallada de la lengua mochica, la cual era vecina y -en ocasiones- convivía con la pescadora, pese a que dicho autor no la menciona. Siglos después, estudiosos posteriores del pasado siglo XX, como Rivet (1949), Rostworowski (1981), Rabinowitz (1983), Torero (1986) y Cerrón-Palomino (1995) se han encargado de comentar algunas de estas fuentes. Sin embargo, la edición de nuevos documentos coloniales nos permite hoy incrementar nuestro conocimiento acerca de esta lengua.

Así, dividiremos este artículo en dos partes. En primera instancia, glosaremos la documentación conocida, estableciendo las disquisiciones e hipótesis que, en su momento, de ellas se hicieron. En esta sección, a su vez, comentaremos las dificultades que entrañan algunas fuentes de estudio y cómo es que las mismas pueden ser subsanadas, mediante una revisión ordenada de las referencias antiguas. Reservaremos la segunda parte para proporcionar las nuevas informaciones con que contamos, a efectos de evaluar lo precedente y de sentar nuestra propia posición al respecto, por medio de la compulsa de lo ya estudiado con los datos que proveen los nuevos documentos que iluminan hoy el horizonte. Los recientes hallazgos no solamente aportan renovados conocimientos, sino que permiten la reinterpretación fundamentada de lo ya conocido.

\section{Estado actual del conocimiento sobre la lengua pescadora}

Lo que se sabe acerca de la lengua pescadora está limitado por los Escasos documentos que de ella hacen mención. No obstante lo cual,

1 La visita de 1605 corresponde a la cuarta visita pastoral del arzobispo Santo Toribio de Mogrovejo y será comentada, recién, a propósito de la lengua pescadora.

2 Quien es nombrado en el estudio de Zevallos Quiñones (1996: 17). Esta fuente tampoco ha sido comentada hasta ahora. 
existen posiciones divergentes con respecto a la interpretación de los mismos. En lo que sigue, presentaremos los textos que hablan sobre la lengua pescadora y cómo es que estos han sido dilucidados. Las fuentes documentales varían según el tipo de información que proporcionan: desde la sola mención de este idioma, sin establecer una posición geográfica; pasando por la designación, acompañada de lugares puntuales donde se habló; hasta la formulación de grandes áreas, en las que se habría empleado la lengua en cuestión. En paralelo, otros documentos históricos brindan testimonios del alcance político del pueblo que habló esta lengua, pero sin referirse a ella. En más de una ocasión se da el caso de que los testimonios del pasado no coinciden en fijar el límite político del pueblo chimú y no sólo eso, sino que incluso los límites políticos no concuerdan con las fronteras lingüísticas. Así, el investigador tiene que ponderar las evidencias para formular sus argumentos.

\subsection{Documentación acerca de la lengua pescadora}

De los autores que proporcionan información de primera mano, el primero que tuvo contacto con la lengua pescadora fue fray Reginaldo de Lizárraga. A pesar de que buena parte de la redacción de su obra pertenece a 1605, Lizárraga declara que llegó al Perú alrededor de 1555. De ahí que consideremos esta fuente como la más antigua. Este autor se refiere, concretamente, al valle de Chicama ([1605] 1968: 13): "Los indios de este valle tienen dos lenguas, que hablan: los pescadores una, y dificultosísima, y la otra no tanto; pocos hablan la general del Inga". El hecho de que se diga que los pescadores como tales tenían una lengua propia es el punto de partida de la hipótesis de Rabinowitz (1983: 243): de que estaríamos ante una lengua especializada de un grupo ocupacional. Las siguientes referencias a la lengua pescadora fueron hechas durante las visitas del arzobispo Toribio de Mogrovejo. Concretamente, durante la segunda visita pastoral, Mogrovejo viajó por la costa norperuana, inquiriendo -entre otras cosas- la lengua de la localidad y si el sacerdote de la misma la conocía. Como resultado de la visita, quedó un diario en donde se anotaron las vicisitudes del recorrido. En él se consigna información variada y valiosa. Lingüísticamente, se obtienen datos de las 
lenguas habladas en la extensa diócesis del arzobispado de Lima, que, a la sazón, era mucho más amplia que la actual. El inconveniente del diario de Mogrovejo fue la vaguedad e imprecisiones con las que se brinda la información, quedando, en más de un caso, lagunas que han sido, frecuentemente, lamentadas. Otra deficiencia en esta fuente radica en que la primera vez que se editó para su divulgación, sólo se publicó una parte de las visitas que realizara el arzobispo limeño. Afortunadamente, se ha reeditado en su integridad el diario de visitas de Mogrovejo, en donde se subsanan algunos de los vacíos que dejó la parcial edición anterior. En efecto, la nueva edición brinda información de la segunda, tercera y cuarta visita que realizara el primado de la iglesia peruana. La edición completa del Libro de Visitas de Santo Toribio incluye la cuarta visita pastoral, hecha a comienzos del siglo XVII, la cual trae noticias que no han sido materia de análisis hasta hoy. Reservaremos estos nuevos datos para la segunda parte de este artículo.

Una dificultad adicional que comporta el diario de Toribio de Mogrovejo es que el detalle cronológico de las visitas no coincide con un desplazamiento lineal en el espacio. Primero puede aparecer información de la costa de Ancash y luego, en vez de venir la información de la costa de La Libertad, sale la concerniente a Lambayeque y luego del norte se pasa otra vez al sur. En nuestro caso, optamos por presentar la información de manera lineal de sur a norte, pues nos interesan los datos sobre las lenguas en el espacio, antes que el periplo exacto de Toribio de Mogrovejo. El itinerario de Mogrovejo se inicia el 17 de julio de 1593 en Carabayllo. Avanza por la costa de Lima hasta Pativilca, para internarse en la sierra austral de Ancash. Luego de visitar pueblos en esa zona, baja a Huarmey en la costa, para subir nuevamente y recorrer la sierra central ancashina, descendiendo, posteriormente, a la altura de Casma en la costa del Pacífico con el ánimo de marchar por Nepeña y Santa. Mogrovejo continuó por la costa de Trujillo y Lambayeque, para, finalmente, internarse en la sierra. Lo que nos incumbe de esta travesía son los datos lingüísticos proporcionados para la zona de la costa que va de Lima a Lambayeque. En el siguiente mapa, aparece el itinerario seguido por Mogrovejo: 


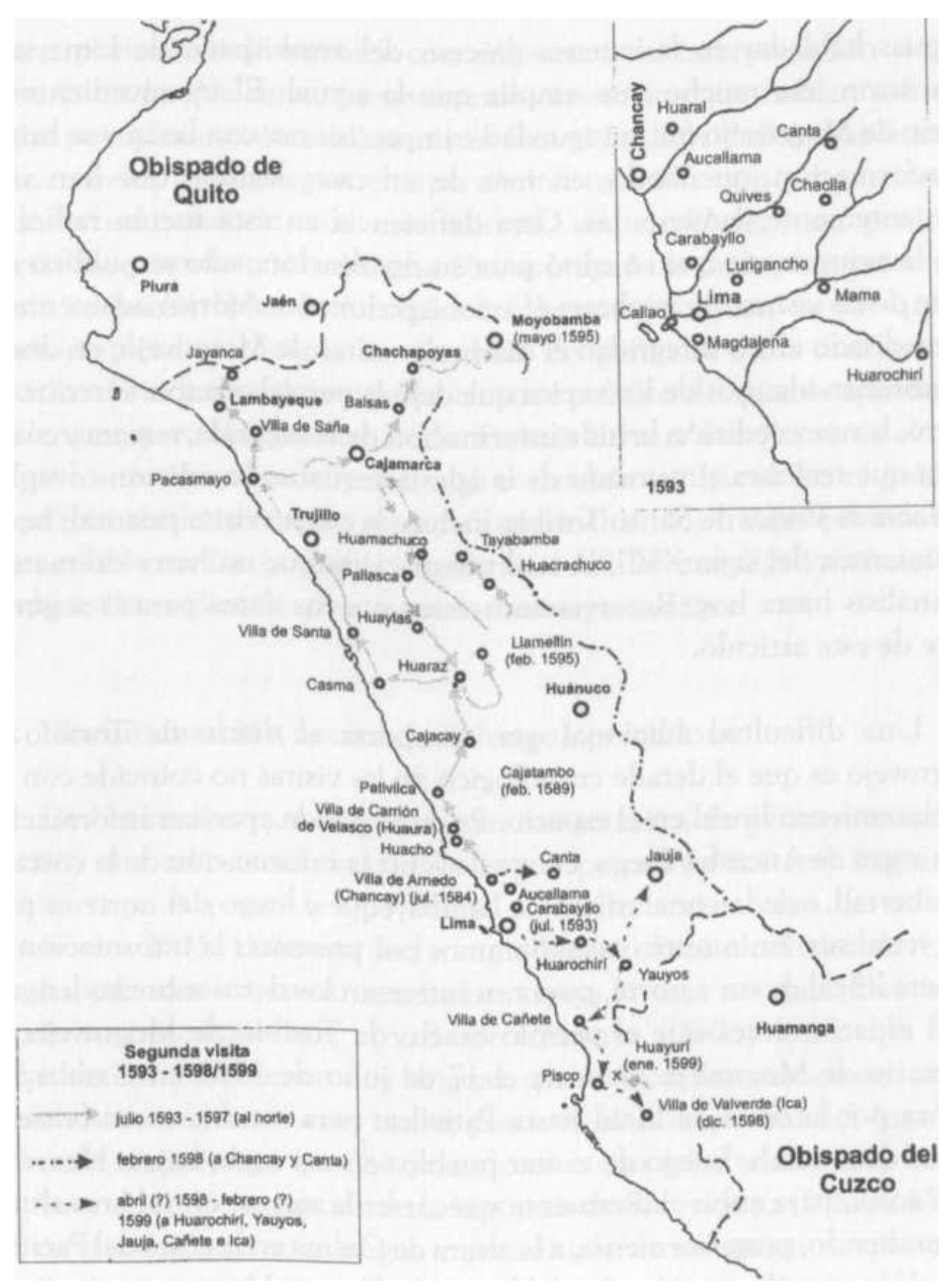

De los pueblos visitados en esta segunda visita pastoral, queda información lingüística sólo de unos pocos. Por lo pronto, diremos que para los pueblos de Huarmey, Santo Domingo de Xanca y Santiago de Guamba (Mogrovejo 11593] 2006: 12-13) se asigna a los indios "la lengua yunga". De ahí se silencia la información lingüística para toda la costa 
de Ancash. Es recién en la región de Trujillo, donde vuelven los datos lingüísticos. Así, se afirma que en Magdalena de Cao (Mogrovejo 2006: 52) se hablan "las lenguas pescadoras" y lo propio se dice del pueblo de Sanctiago de Cao (Mogrovejo 2006: 52) con relación a la pescadora. Para Jequetepeque (Mogrovejo 2006: 50), se deja constancia de que la lengua del lugar es la yunga, tal como en el pueblo de Chepén (Mogrovejo 2006: 50). Para Mocupe (Mogrovejo 2006: 48) se indica que el sacerdote "sabe un poco-la lengua yunga, que es la que hablan los indios." En Magdalena de Eten (Mogrovejo 2006: 48) se aporta la noticia de que el sacerdote del pueblo "sabe bien la lengua yunga pescadora, pues es la que hablan los indios." Para San Martín de Reque (Mogrovejo 2006: 45), el sacerdote "sabe muy bien la lengua yunga que es la que hablan los indios de la dicha doctrina." En los pueblos de Monzebú y Callanca (Mogrovejo 2006: 46) se utiliza "la lengua yunga que es la que hablan los indios deste pueblo y doctrina". En San Miguel de Farcapa y San Francisco de Chiclayo (Mogrovejo 2006: 44), el idioma en uso es "la lengua materna yunga destos valles". En Lambayeque (Mogrovejo 2006: 43) se da a conocer que el sacerdote es "examinador de la lengua mochica que se habla en estos valles". Por su parte, Ferreñafe (Mogrovejo 2006: 40) es un pueblo de "lengua materna yunga", mientras que para Mochomí y Túcume (Mogrovejo 2006: 42) se asevera que sus sacerdotes "saben la lengua materna destos llanos que hablan los indios". Mogrovejo nombra como uno de estos sacerdotes de Túcume a Hernando de la Carrera, pero sin mencionar cuál es dicha lengua materna. Sin embargo, es conocido que en 1597 el sacerdote Hernando de la Carrera, quien se desempeñara en tales pueblos pasó examen de conocimiento en la lengua yunga (Rostworowski 1981: 99). ${ }^{3}$ Podemos descartar así que sea un pueblo de habla quechua.

3 No ha de confundirse a Hernando de la Carrera, citado en este pasaje, con Fernando de la Carrera, autor del Arte de la lengua yunga. El primero sería abuelo del segundo, a estar por una información proporcionada, póstumamente, por Zevallos Quiñones (11948] 2003: 376). Lo que acontece es que, en el año 2003, la Revista del Museo de Arqueología, Antropología e Historia de la Universidad Nacional de Trujillo reedita una selección de los principales artículos de don Jorge Zevallos Quiñones, fallecido en 1997. Dentro de estos trabajos está el ya clásico artículo sobre "Los gramáticos de la lengua yunga", publicado por vez primera hacia 1948. La novedad de esta reedición es que en los apéndices aparecen valiosos documentos ausentes en el texto 
Finalmente, se señala al pueblo de San Juan de Illimo (Mogrovejo 2006: 40) como localidad con la "lengua materna de los yungas". En resumen, el Libro de visitas de Mogrovejo da a conocer que de Huarmey hasta Illimo se habla una lengua que se rotula como yunga, puntualizando que en Santiago y Magdalena de Cao se habla la pescadora, así como en Eten. Se reserva, finalmente, a Lambayeque como pueblo de lengua mochica.

Como se puede ver, la información tiene vacíos, que pueden, empero, ser subsanados por otros documentos que son más precisos. De lo que podemos estar seguros es del uso general que se le da al término yunga, que designaría a más de una entidad lingüística. Lo que más llama nuestra atención es la asignación de la lengua pescadora para el pueblo de Eten, que fue el último bastión de la lengua mochica hasta su desaparición en la primera mitad del siglo XX. Rostworowski (1981: 99) interpreta esto como síntoma de ser una lengua propia de personas dedicadas a la pesca. La autora considera que la lengua pescadora habría servido como lingua franca, facilitadora de la comunicación a lo largo del litoral, en tanto lengua técnica de un grupo socioeconómico marginado por los agricultores. Esta postura asume la especialización sociolingüística de un grupo como los pescadores que se habría valido de una lengua técnica para su comunicación.

Sobre este mismo punto, Rabinowitz (1983: 257) establecía dos posibles hipótesis: la primera es que la lengua pescadora se habría utilizado, ininterrumpidamente, desde Virú por el sur, hasta Lambayeque por todas las villas de pescadores. Rabinowitz aclara que esta hipótesis se formula con cargo a encontrar nuevos documentos. La segunda hipótesis de Rabinowitz sería que los chimúes habrían trasladado sus pescadores hacía el norte de Chicama para consolidar sus territorios. La mención de

Uno de los cuales es el acta de matrimonio de los padres del gramático Fernando de la Carrera (Arch. Parroq. Sagrario, lib. Bautismos $\mathrm{N}^{\circ} 1$, f. 118). Curiosamente, los progenitores de este gramático fueron casados por su abuelo, quien tras enviudar tomó los hábitos. Por ello es que se le menciona como sacerdote de un pueblo de la costa norperuana. Asimismo, esta reedición nos permite saber que Fernando de la Carrera nace recién en 1604 (Arch. Arzob. de Trujillo: Leg. 10, cuad. 1), por lo que sería imposible que haya sido cura hacia 1597. 
la lengua pescadora en Magdalena de Eten sería la única evidencia para esta segunda hipótesis. Con respecto a la lengua pescadora en Magdalena de Eten, Cerrón-Palomino (1995: 31) plantea que o bien puede tratarse de un error, o bien serían mitmas llevados del sur. Torero (1986: 534), por su parte, llama la atención sobre la vaguedad de la referencia del vocablo pescadora. Nosotros nos inclinamos por creer que el término pescadora, en el caso de Magdalena de Eten, fue usado de manera informal y sin ningún ánimo de ser exactos en la designación. Así, sería como también se usó a propósito del pueblo de Magdalena de Cao, en el que se hablaban "las lenguas pescadoras" y tal sería la manera como, en 1616, Alonso de Huerta ([1616] 1993: 17) informa que en los valles de Trujillo se habla la lengua pescadora. De este mismo modo, Bernabé Cobo ([1653] 1964b: 235) reconocía el alcance que tuvo esta entidad lingüística cuando escribió que "la [lengua] de los indios de Trujillo corría muchas leguas por la costa de la mar".

Con todo, el diario de Mogrovejo es valioso, porque nos hace conocer la existencia en la costa norte de idiomas no quechuas y, a su vez, por dar indicios que bien pueden ser contrastados con fuentes un poco más exactas, a efectos de determinar la distribución de la lengua pescadora. Dos documentos mencionan la distribución, pueblo por pueblo, de las lenguas de lo que, actualmente, es Lambayeque y La Libertad: La Memoria de las doctrinas que ay en los valles del obispado de Truxillo desde el rio Sancta asta Colán, lo último de los llanos, cuya fecha discutiremos en breve y el Arte de la lengua yunga de Fernando de la Carrera (1644). El primer documento fue encontrado en 1950 por Josefina Ramos Cabredo y proporciona información tanto del mochica como de la lengua pescadora. De aquí en más, denominaremos esta memoria como documento Ramos. El segundo restringe su información al ámbito del idioma mochica, pero al cruzar la información con el primer documento se puede tener una idea cumplida de la distribución de las lenguas habladas en la zona, a efectos de contrastar esto con lo que nos hace saber Antonio de la Calancha.

El original del documento Ramos se encuentra entre los papeles de Vargas Ugarte y tiene escrito en el dorso 1638. Rostworowski (1981: 99) proporciona datos que llevarían a pensar que la redacción del documento 
Ramos se ubica en un rango que va de 1603 a 1633 . No obstante, nuevos testimonios nos acercan más en la fecha de dicho documento. En el documento Ramos se lee que Pedro Prado era cura de Reque y que Fernando de la Carrera se encontraba "sin beneficio opositor al curato de Jayanca". Asimismo, se dice que la lengua pescadora "la sabe el padre $\mathrm{Jul}^{\circ}$ Pacheco, clérigo, cura propietario de Jayanca en los valles. Y no otro alguno." En cuanto a la fecha más temprana de redacción, Zevallos Quiñones (1948: 47 y 50-51) escribió que Pedro Prado llegó a ser cura de San Martín de Reque en 1630 y que en ese mismo año se encontraba De la Carrera en Jayanca, tal como lo afirma el documento Ramos. Por lo que hace a la fecha de redacción más tardía, el mismo Zevallos Quiñones (1996: 17) nos deja saber que el 12 de mayo de 1631 dos nuevos sacerdotes habían absuelto el examen de proficiencia en lengua pescadora. Así, el límite superior sería el 12 de mayo de 1631 y el inferior, el año de 1630. Ahora bien, nos inclinamos a pensar que el documento Ramos sería de 1630, pues según el mismo documento publicado por Zevallos Quiñones (1996: 17) se mencionan varios examinadores “en la lengua pescadora". Además de Pacheco, estarían Jacinto de la Cruz y Pedro de Estupiñán. De manera tal que la exclusividad del padre Pacheco debe corresponder al año anterior del límite superior de antigüedad que hemos establecido. Para el corregimiento de Trujillo el documento Ramos da la siguiente distribución lingüística:

\section{“Corregimiento de Truxillo}

1.- Guañape y Viru es un beneficio de frailes mersenarios.

2.- Moche y Guaman otro beneficio de Mersenarios.

3.- Sanc Estevan. De los curas de la Catedral.

4.- Mansiche y Guanchaco de Franciscos.

5.- Sanctiago de Dominicos.

6.- Cao. De Dominicos. y en todas estas doctrinas se abla la lengua pescadora. Y la sabe el padre $\mathrm{Jul}^{\circ}$ Pachecho, clérigo, cura propietario de Jayanca en los valles. Y no otro alguno.

7.- Chocope. De Dominicos.

8.- Payzan. De Mersenarios. 
en estos dos beneficios se habla la lengua de los valles que es la que llaman quichua o mochica.

Otros tres pueblos ay en este corregimiento de Truxillo que son de los Agustinos. Y en ellos se abla la lengua general, porque de ellos comiensa la Sierra."

El documento Ramos permite saber que la lengua pescadora se hablaba en Santiago y Magdalena de Cao, Huanchaco, Mansiche, San Esteban, Huamán, Moche, Virú y Guañape. En el mapa 2 se aprecia la ubicación de estos pueblos. Ahora, existe una coincidencia para los pueblos de Santiago y Magdalena de Cao con la alusión a la lengua pescadora que brindara, de un lado, Lizárraga para Chicama, pues tanto Magdalena como Santiago de Cao se ubican en dicho valle y, de otro, Toribio de Mogrovejo. Empero, resulta insuficiente para conocer la situación lingüística de la zona meridional en Huarmey, pueblo cuya información lingüística fue, insuficientemente, reseñada por Mogrovejo. El documento Ramos, a su vez, brinda la distribución de pueblos, en los que se habló la lengua mochica. Así, para el corregimiento de Trujillo, señala Chocope y Paiján; para el corregimiento de Chiclayo: San Pedro de Lloco, Jequetepeque, Guadalupe, Pueblo Nuevo, Mocupe, Reque, Monsefú, Callanca, Chiclayo y San Miguel; para el corregimiento de Zaña: Lambayeque, Ferreñafe, Mochumí, Íllimo, Túcume, Motupe, Jayanca y Pacora. De la Carrera (1644), ${ }^{4}$ por su parte, proporciona la "Razón de todos los beneficios", donde se habla el mochica. Así, para la zona costera del obispado de Trujillo, De la Carrera revela que el mochica se hablaba en el corregimiento de Trujillo: en Santiago y Magdalena de Cao, Chocope, todo el valle de Chicama y Paiján; y en el corregimiento de Zaña: en San Pedro de Lloc, Jequetepeque, Chepen, Guadalupe, Pueblo Nuevo, Eten, Chiclayo, San Miguel, Santa Lucía Parroquia de Zaña, Reque, Monsefú, Ferreñafe, Mochumí, Lambayeque, Túcume, Íllimo, Pacora, Mórrope y Jayanca. Con estas informaciones, elaboramos el siguiente mapa que nos da la distribución, pueblo por pueblo, de las lenguas mochica y pescadora:

4 La "Razón de todos los beneficios", donde se utilizó el mochica se encuentra en página sin numerar, al inicio del Arte de la lengua yunga de 1644.

Bol. Acad. peru. leng. 50(50), 2010 


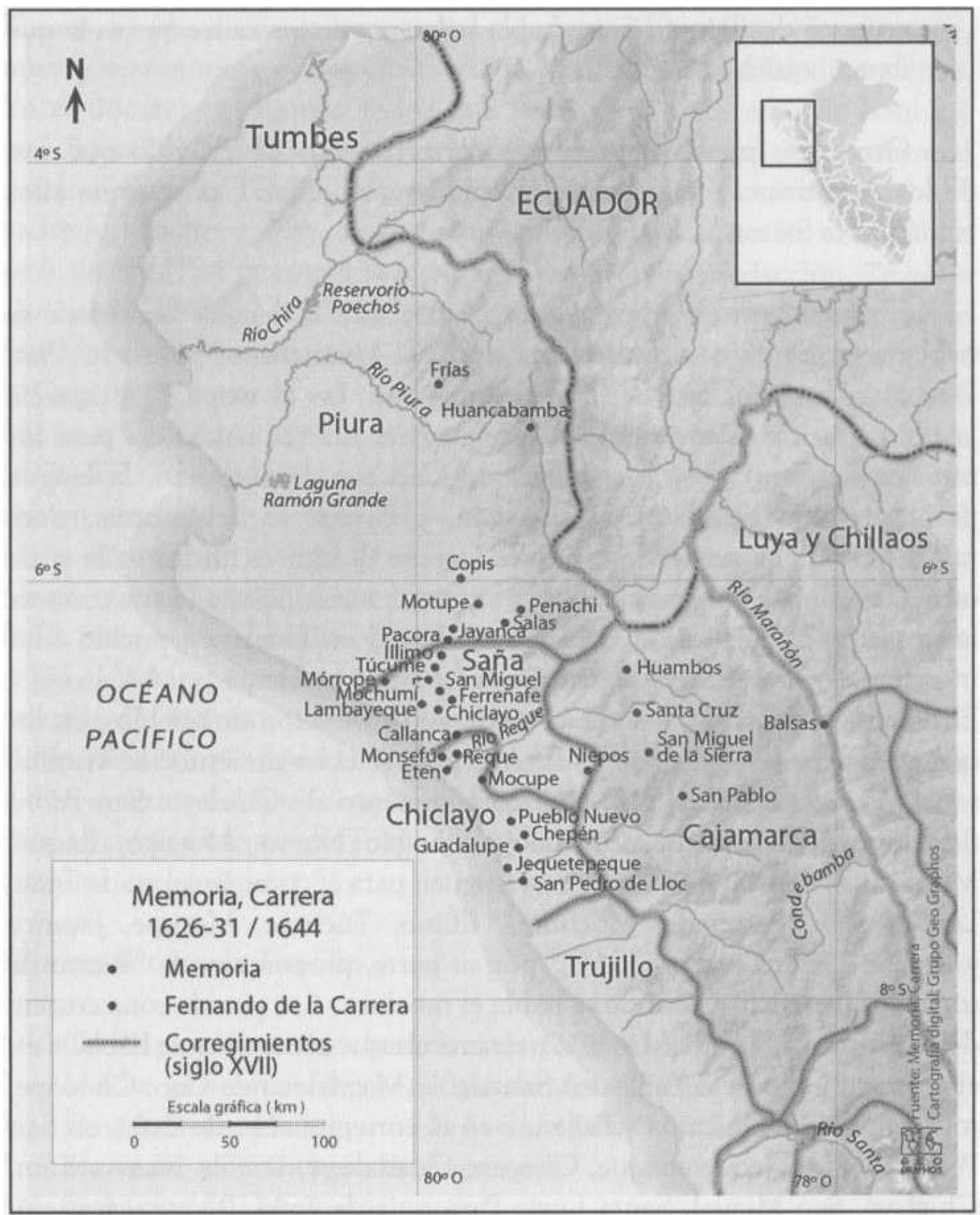

Si extrapolásemos la información del documento Ramos y del Arte de la lengua yunga del cura De la Carrera para aplicarla a la segunda visita de Mogrovejo, obtendríamos que tanto el mochica como la pescadora se habrían hablado en Santiago y Magdalena de Cao, El resto de pueblos desde Jequetepeque hasta San Juan de Illimo serían de habla mochica, mientras 
que para los pueblos de Huarmey, Santo Domingo de Xanca y Santiago de Guamba no podríamos determinar cuál es la lengua yunga hablada en aquel tiempo, al menos a partir del documento Ramos y del Arte de 1644.

\subsection{Panorama lingüístico de la lengua pescadora}

Contando con los datos del itinerario de la segunda visita de Mogrovejo, del documento Ramos y del Arte de 1644, tenemos suficiente información de fondo para abordar el panorama lingüístico que planteara en la primera mitad del siglo XVII, el agustino Antonio de la Calancha. Es a partir de la interpretación de este autor que se fijan las posiciones de los estudios actuales, con relación a la lengua pescadora. Dos son los temas cruciales abordados por De la Calancha, los cuales han estado sujetos a interpretaciones y reinterpretaciones sucesivas. El primer gran tema es la delimitación de las áreas estrictamente lingüísticas, con respecto a la hegemonía política de los chimúes. Sobre este punto, además de Antonio de la Calancha, hemos hallado autores que van de 1542 a 1793, los cuales dan distintas fronteras para los chimúes. Reservaremos esto para la siguiente parte del artículo. La segunda cuestión de fondo es la determinación de las lenguas en uso en la costa norperuana. Sobre este punto, las opiniones divergen, según las elucidaciones que se presten a dos pasajes de la obra de Antonio de la Calancha. Sin embargo, creemos que el panorama se clarifica si se tiene en mente un tercer pasaje que no fue considerado, en su momento, ni por Rivet ni por Rabinowitz. Así pues, el cronista De la Calancha proporciona la siguiente visión de la realidad lingüística ([1639] 1977: 1235):

"Un Cazique de lo que oy se llama Trugillo, llamado el Chimo, siendo de natural brioso, de ánimo alentado, i de coraçón anbicioso, a imitación de los Ingas del Cuzco (que sienpre las acciones valerosas crían enbidias, i animan desalientos) fue conquistando los Indios Yungas, i aziendo tributarias las Provincias destos llanos desde Paramunga, asta Payta i Tunbes, cobrando tributos en ropa i comidas, i obligando a seys mil Indios a que de las sierras le trugesen oro, plata, chaquiras i cobre; hízose opulento, creció en vasallos, i fuese introduciendo en magestad su lengua natural, que 
es la que oy se abla en los valles de Trugillo, era la Quingnam propria deste Reyezuelo; i así por lisongearle su memoria, se llamó la Provincia del Chimo; los vasallos de Pacasmayo dieron en ablar su lengua, i los demás asta Lima, aunque corronpidos algunos vocablos; los demás valles de los llanos ablavan la lengua Muchic, que oy conservan asta Motupe, i otra que llaman Sec; i la de los Olmos mudan letras i finales, si bien cada pueblo, i aun cada familia tiene tiene lengua propria, o vocablos diferentes, siendo la confusión de sus lenguas castigos de Babilonia, pues izo a los principios la multitud dellas casi enmudecer a los Predicadores; que si el Espíritu santo da don de lenguas i baja en fuego, el Demonio multiplica lenguas i confunde idiomas, porque se estorve la Fe, i bajen a su fuego infernal. La que entre ellos se llama la Pescadora, más parece lenguage para el estómago, que para el entendimiento; es corta, escura, gutural i desabrida; con estas dos lenguas más comunes se tenía la correspondencia de los valles, i se manejava mucho el comercio i contrataciones destos territorios.

"Chimos se fueron llamando los señores, i llegaron a estender su jurisdición i vasallaje asta Parmunca, treynta leguas i más apartado de Lima.”

Dejando de lado la cuestión de las lenguas de Piura, la jurisdicción de los chimos habría ido desde Tumbes a Paramonga, pero el uso de la lengua quingnam habría sido de Pacasmayo hasta Lima en la época de mayor auge, de acuerdo con el cronista De la Calancha. Como veremos en la segunda parte, autores anteriores y posteriores fijarán límites políticos distintos a los establecidos por De la Calancha. Con todo, preciso es señalar que De la Calancha distingue dos momentos en el uso de la lengua quingnam. Este punto es de mayor relevancia, porque el mismo autor menciona que la lengua quingnam "oy se abla en los valles de Trugillo" y esto no coincide con la época de mayor auge: "De Tumbes a Paramonga".

La distribución de la lengua quingnam que brinda el agustino De la Calancha coincide, parcialmente, con la Historia Anónima de 1604 (Vargas Ugarte 1936: 231), según la cual los chimúes habrían conquistado 
tempranamente Pacasmayo, bajo el mando de Nañcen Pinco, nieto de Taycanamo. Sin embargo, existe discrepancia entre la Historia Anónima y De la Calancha con respecto al alcance político que tuvieron los chimos, pues la primera manifiesta que llegaron hasta Carabayllo, mientras que De la Calancha solamente extiende su poder hasta Paramonga. Véase, en el mapa, el detalle de las conquistas tempranas de los chimúes, con el alcance total de su territorio en los tiempos de mayor expansión:

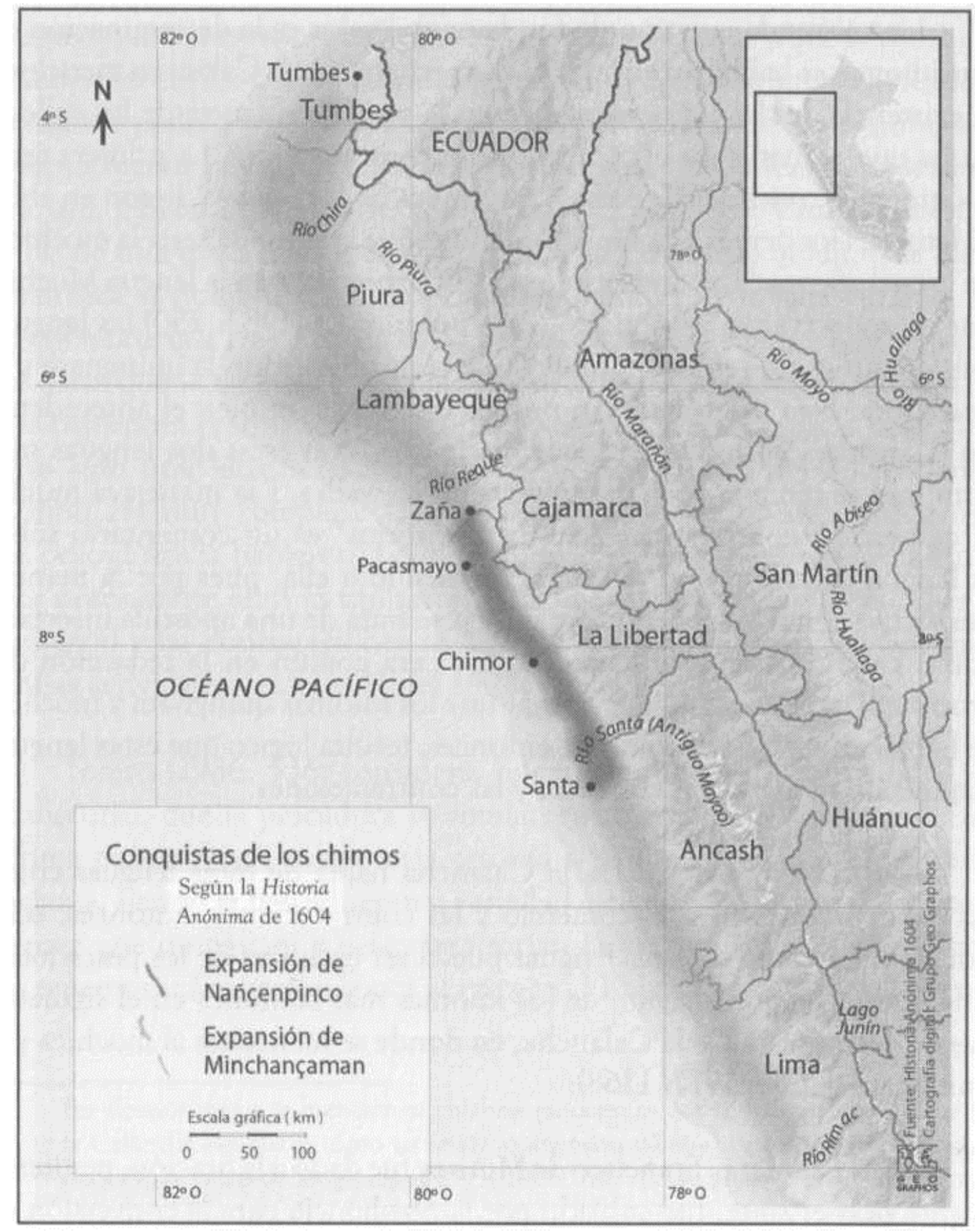

Bol. Acad. perú. leng. 50(50), 2010 
A la espera de solución, permanece el alcance de la lengua quingnam por el sur, toda vez que la extensión mayor que alcanzara el quingnam por meridión habría excedido con mucho lo señalado en la Historia Anónima de 1604, a propósito de las conquistas tempranas de Nañcen Pinco; mas no, con respecto a las ocupaciones tardías de Michancaman. Con todo, esta cuestión recién podrá ser revisada con los aportes que aparecen en la segunda parte del artículo.

Una segunda cuestión de fundamental valor es la determinación de qué idiomas se hablaban en la costa norperuana. De la Calancha menciona la existencia de dos lenguas que tenían la correspondencia de los valles y en las que se manejaba el comercio y las contrataciones. La primera sería la quingnam, pues de ella dice: "Los vasallos de Pacasmayo dieron en ablar su lengua, i los demás asta Lima", mientras que la segunda sería la mochica, de la cual afirma: "Los demás valles de los llanos ablavan la lengua Muchic, que oy conservan asta Motupe". Para Rabinowitz (1983: 250) las lenguas más comunes no serían la quingnam y la mochica, sino la quingnam y la pescadora. Esta interpretación nos parece errada. Si bien el antecedente de la afirmación de De la Calancha de que "con estas dos lenguas más comunes se tenía la correspondencia de los valles, i se manejava mucho el comercio i contrataciones destos territorios" es un comentario sobre la lengua pescadora; no se estaría refiriendo a ella, pues por la manera despectiva como la menciona, más bien se trata de una apostilla insertada como paréntesis en el discurso, lo cual era común en la redacción del cronista. Por su parte, al mencionar que los idiomas quingnam y mochica se hablaban en más de un valle, entonces, resulta lógico que estas lenguas hayan sido usadas en el comercio y las contrataciones.

Ahora bien, cuando De la Calancha habla de estas lenguas como las más comunes para el comercio y las contrataciones, entonces, echa por tierra que una de estas lenguas pueda ser exclusiva de los pescadores. Encontramos confirmación de los idiomas más comunes en el siguiente pasaje del cronista De la Calancha, en donde se menciona al mochica y al quingnam ([1639] 1977: 1368):

"El Padre fray Francisco de Monroy fue dado a la oración, penitente i observante; fue enbiado por la obediencia para la conversión de 
los pueblos de san Pedro de Yoco, i Xequetepeque, entonces de gran gentío, $i$ en tributarios de numerosa multitud, es la lengua que ablan la Muchic i la Quingnam, escura i de escabrosa pronunciación. La pescadora es en lo general la misma, pero usa más de lo gutural; pocos la an sabido con perfeción, i destos nuestros Religiosos la an compreendido con eminencia"

Este pasaje ha recibido más de una interpretación. Rivet (1948: 10) planteó que la pescadora es lo mismo que la quingnam y que la mochica. Rabinowitz (1983: 261) va más allá, argumentando que la lengua pescadora no habría podido ser entendida por los hablantes de mochica o quingnam que no fueran pescadores. Rabinowitz especula que la lengua pescadora era una lengua diferente del quingnam y el mochica. Esto también es fruto de una mala lectura de Antonio De la Calancha, quien, más bien, identifica al quingnam con la pescadora, como una misma entidad. La distribución que De la Calancha da para el quingnam cuadra muy bien con los datos que se tiene de la lengua pescadora. Nuevamente, si el quingnam y la pescadora eran la misma entidad, no tiene sentido que la pescadora haya sido una lengua exclusivamente de pescadores, pues la sociedad Chimú era muy compleja. Con toda seguridad, se puede afirmar que los pescadores la hablaron, pero definitivamente no es posible garantizar que únicamente ellos la utilizaron. Máxime si se tiene en cuenta que el comercio y las contrataciones se habrían realizado en esta lengua, pues ambas actividades trascienden el ámbito de la pesca.

Torero (1986: 536) considera, por una relación de contigüidad en el discurso, que la pescadora es similar, solamente, a la quingnam. Esta última posición nos parece más cercana a la interpretación que e texto reclama, siendo la pescadora una variedad estigmatizada. Esto da pie para pensar que quingnam y pescadora serían la misma lengua, aun cuando no tenemos información léxica al respecto. ${ }^{5}$ Rostworowski (1981: 98), por

5 En algunos textos se mencionan palabras autóctonas que se hallarían en lo que De la Calancha estableció como territorio quingnam, tal es el caso del siguiente pasaje del Libro de visitas de Mogrovejo ([1593] 2006: 37): “á cuyo cause se crían en él mucha abundancia de cañizales, a quien los naturales llaman pez; su propio nombre Sancha, y 
su parte, estima como dudosa la noticia del idioma quingnam. Para esta autora, habrían existido dos lenguas: la yunga o mochica y la pescadora: Una, hablada por los habitantes de los valles y la otra, por los pescadores de manera exclusiva. Estamos convencidos de que la lengua pescadora, por haber sido empleada en una región geográfica próxima al Pacífico, debió de ser hablada por los pescadores; aunque no encontramos suficiente fundamento para considerar que, únicamente, las personas dedicadas a la pesca hayan hablado dicho idioma.

Un pasaje final, inadvertido u olvidado por Rivet y Rabinowitz, en el que se cumpliría, de un lado, la identidad de la quingnam y la pescadora y, de otro, el que la lengua mochica fuera, junto con las anteriores, una de las dos lenguas más comunes; es el siguiente (Calancha [1639] 1976: 835):

“(...) todas las naciones nonbran a Dios con palabra, que significa lo mesmo que Tetragrammaton, que en Quichva, i Aymara le llaman Guaca. Los marítimos pescadores Vini, los lungas Mochicas dicen Alec, los Puquinas Coac, nonbres de quatro letras, i eso significa Tetragrammaton en Griego, que en Ebreo es Jeovath, i son quatro letras, lod, He, Vau, He. i los pütillos sirven de vocales, i así entre ellos como entre éstos, quiere decir, el que causa de todo."

Todas las lenguas arriba citadas son lenguas generales. Por una simple inferencia se puede determinar que los "marítimos pescadores" son los hablantes de la lengua pescadora y, por el mismo proceso de inferencia, podemos establecer que si la quingnam y la pescadora eran una misma lengua, entonces, tiene sentido que no se mencione a la quingnam, ya que la pescadora ha sido aludida. De paso, hay que decir que Vini sería una palabra propia de la lengua quingnam o pescadora, cuyos nombres de aquí en más utilizaremos como designaciones de una misma entidad.

En cuanto al nombre de 'pescadora', De la Calancha afirma que dicha lengua era llamada así entre los naturales de la costa. Torero (1989: 229)

por esta causa se derivó llamarse todo el valle Sancta, y cuando se pobló la dicha villa por no quitarle el nombre propio y darle el que le cuadrase la instituyó y pusieron la villa de la Sancta María de la Pavilla." 
formula una hipótesis acerca del origen de tal nombre en tanto traducción de guaxme, 'pescador'. Revisando el lexicón quechua de Domingo de Santo Tomás ([1560] 1951: 136), está precisamente la palabra guaxme con el significado de 'pescador'. Del mismo modo, nombra grupos humanos señalados por Guarnan Poma ([1615] 1993: 744 y 872) como Uachimi yunga y Latayunga Uachime en apoyo de su hipótesis, vinculando a estos grupos con los designados como guachemines en la Crónica de los Agustinos de Huamachuco. ${ }^{6}$ Conjeturamos que es acertado asignar como étimo de los guachemines de la Crónica de los Agustinos de Huamachuco la palabra guaxme, 'pescador', aun cuando no necesariamente corresponda esto al origen del término pescadora, como glotónimo. No olvidemos que el término guaxme aparece en Domingo de Santo Tomás y es de origen quechua, hasta que se demuestre lo contrario.

De otro lado, en un examen de la gramática mochica de Middendorf, Schaedel (citado por Rabinowitz 1983: 264) analizaba la palabra quingnam como un nombre verbal formado por una raíz verbal king- 'hilar' y un supino -näm, haciendo una suerte de metáfora, en la que los chimúes hablarían como hilando. El problema con esta etimología es que se usa la lengua mochica para explicar otra lengua que no lo es. Formalmente, pueden existir coincidencias, pero no hay una correlación entre ambas

$6 \quad$ He aquí los pasajes pertinentes de la Crónica de los Agustinos ([1560] 1992: 17-18): “(...) Ataguju envió a el mundo desde el cielo a este Guamansuri; y éste vino a el mundo a la provincia de Guamachuco, que allí se avía de començar, y quando vino halló en él a unos cristianos que en lengua de Guamachuco se llaman guachemines [...]. Tenían estos guachemines una hermana que llamavan Captaguani, la qual tenían muy encerrada que no la veya nadie, y un día fueron los hermanos fuera y entonces Guamansuri fue a ella y con halagos y engaños la uvo y emprenó [...]. Este Catequil fue adonde murió su madre y resucitóla, y entonces la madre dióle dos guaracas o hondas que su padre Guamansuri avía dexado para que las diese a los que pariese, para que con aquellas avía de matar a los guachemines, y entonces dize que el fuerte mancebo mató a los guachemines y a algunos que quedaron echólos de la tierra; entonces subióse a el cielo, y díxole a Ataguju: "Ya la tierra está libre y los guachemines muertos y echados de la tierra, agora le ruego se crien yndios que la habiten y labren". Ataguju respondió que pues lo avía hecho tan fuertemente y avian muertos los guachemines, que fuese a el cerro y puna quellos llaman que se llama Guacat, encima de Sancta, ques donde agora está fundada la Villa de la Parrilla, entre Trujillo y Lima [...] y cabasen con taquillas o açadas de plata y oro y de allí sacaría los yndios, y de ahí se multiplicarían (...)" 
entidades lingüísticas. Así, la hipótesis de Schaedel no pasa de ser una etimología popular. Por nuestra parte, creemos que el mismo término quingnam debe haber significado 'pescador' en dicha lengua, pues eran los mismos hablantes que denominaban de esta manera a la lengua, tal como nos lo deja saber Antonio De la Calancha.

\subsection{Límites de la lengua pescadora}

Antonio De la Calancha es el cronista que establece que los límites del quingnam o pescadora en su época de mayor auge serían por el norte, hasta Pacasmayo y Jequetepeque; y por el sur, hasta Lima. Empero, si consideramos los datos que el documento Ramos aporta sobre la lengua pescadora, ésta sólo se habría hablado por el norte hasta el valle de Chicama, excluyendo así el de Pacasmayo. Esto se resuelve atendiendo al texto que ofrece De la Calancha, en el cual señala que la quingnam "es la que oy se abla en los valles de Trugillo". Así, lo que es preciso establecer es cuáles son los valles de Trujillo en los que se hablaba la lengua quingnam en los tiempos en los que De la Calancha escribe, para diferenciarlos de la época de mayor auge a la que se refiere. A su turno, el contraste con la distribución dada por De la Calancha para el quingnam, de un lado; y, de otro, por De la Carrera y el documento Ramos, exclusivamente para el mochica, nos habla de una situación en la que ambas lenguas estarían en uso en la zona que va de Pacasmayo a Chicama, pero en la época de mayor expansión de los chimúes.

Por su parte, la información sobre el uso austral de la lengua pescadora, proporcionada en el mismo documento Ramos llega, solamente, hasta Virú, lo cual nos impide verificar el alcance meridional de la lengua quingnam de acuerdo con lo establecido por De la Calancha.

\subsubsection{Límite septentrional}

De la Calancha afirma que los vasallos de Pacasmayo empezaron a hablar la lengua quingnam. Como vimos, según la Historia Anónima de 1604 publicada por Vargas Ugarte (1936: 231), los chimúes habrían 
conquistado tempranamente Pacasmayo, bajo el mando de Nañcen Pinco, nieto de Taycanamo. La precoz conquista de dicho valle hace que sea factible el arraigo del quingnam en Pacasmayo. Luego afirma que en San Pedro de Lloc y Jequetepeque se hablaba el muchic y el quingnam, y que la pescadora es en general lo mismo que este último. Todas estas localidades se encontrarían en la zona bañada por el río Jequetepeque. No obstante, De la Calancha, además, da una serie de términos usados en Pacasmayo, que curiosamente son todos de origen mochica: sian 'casa de la luna' (Calancha [1639] 1977: 1239), ni 'mar' (Calancha [1639] 1977: 1241), alecpong 'deidad en piedra' (Calancha [1639] 1977: 1242), fur 'año' (Calancha [1639] 1977: 1244), oquetlupuc 'médico' (Calancha [1639] 1977: 1248). Esto es una prueba de que la convivencia entre mochica y pescadora empezaba por el norte en el valle de Jequetepeque y continuaba hacia el sur. He aquí un mapa donde se identifican los pueblos y ríos mencionados:

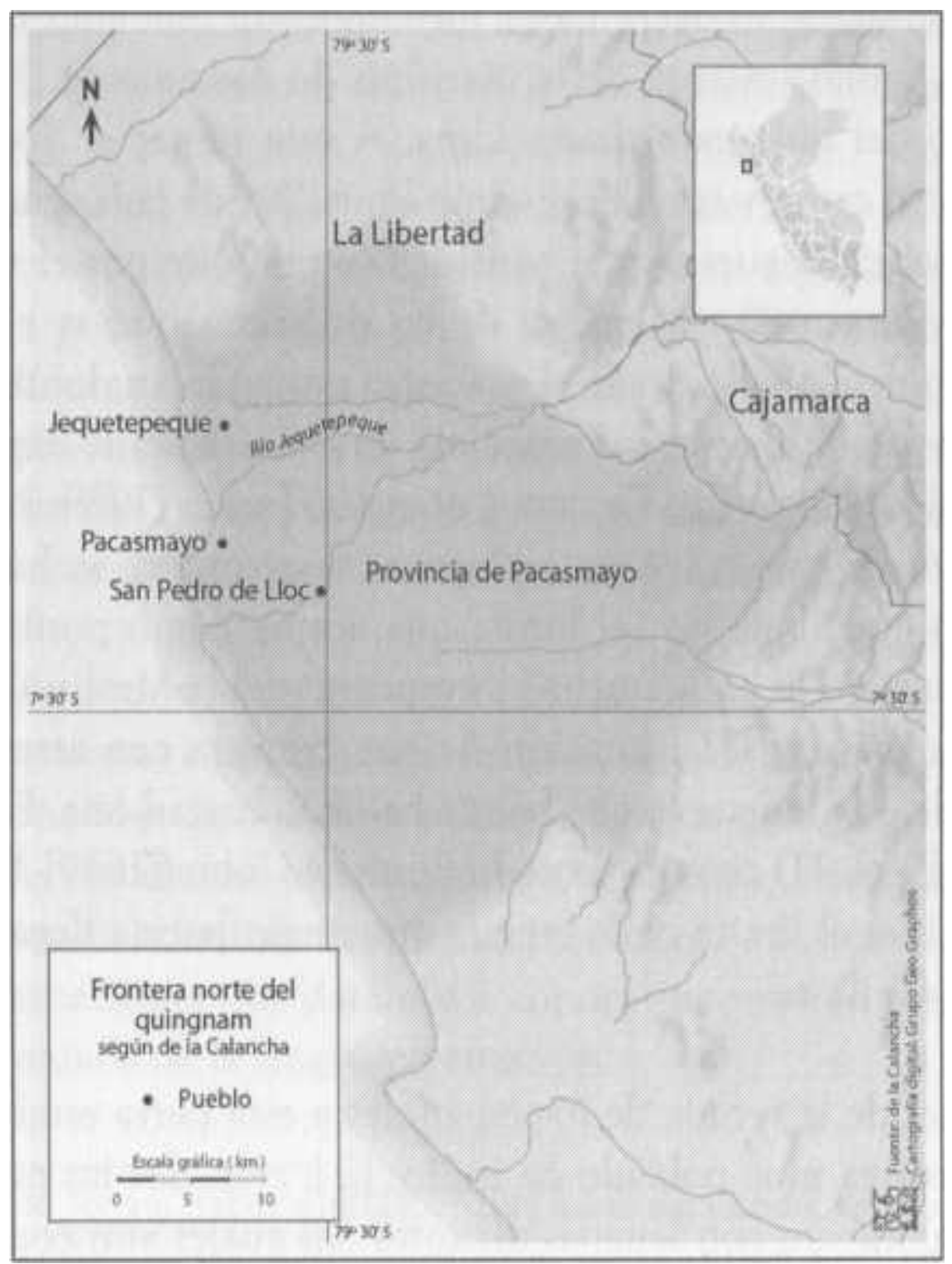

Bol. Acad. peru. leng. 50(50), 2010 
El mapa ayuda a establecer que no hay que confundir entidades como la provincia de Pacasmayo con el pueblo de tal nombre, ni el río Jequetepeque con el pueblo homónimo. El mencionado pueblo de San Pedro de Lloc está al sur del puerto de Pacasmayo y Jequetepeque, al norte del mismo. El río que baña la provincia de Pacasmayo es, justamente, el río Jequetepeque. Razón por la cual el límite septentrional de la lengua quingnam era el valle de Jequetepeque que se encuentra en la provincia de Pacasmayo, cuyo nombre designa tanto al puerto como a la provincia.

\subsubsection{Límite meridional}

La distribución austral de la pescadora y el mochica que se obtiene a partir de la segunda visita de Mogrovejo, el documento Ramos y De la Carrera corresponde con lo aseverado por De la Calancha a propósito de la distribución del mochica y el quingnam, por lo menos hasta donde se cuenta con datos, es decir, hasta Virú, dejando una gran interrogante hacia el sur, habida cuenta de la mención de Antonio De la Calancha sobre el uso del quingnam hasta Lima. A este respecto, Torero (1986: 540) se mostró cauto y estableció como límite sur de la lengua pescadora el valle de Santa. Seguramente, consideró este límite por el nombre del documento Ramos: "La Memoria de las doctrinas que ay en los valles del obispado de Truxillo desde el rio Sancta asta Colán, lo último de los llanos", a pesar de que la información, lingüísticamente explícita, sólo llega hasta al valle de Virú. Tres años después, Torero (1989: 229) planteó la posibilidad de que la lengua quingnam o pescadora se haya hablado hasta Paramonga. Esta vez, el límite que acepta como posible coincide con lo dicho por De la Calancha, a propósito del control político de los chimúes. No así con la afirmación de este cronista con respecto al uso lingüístico de esta lengua que se habría hablado hasta Lima. Por su parte, Paul Rivet (1949: 11) cita un texto de Bernabé Cobo ([1639] 1964a: 301), planteando que el límite de la lengua quingnam habría llegado hasta el valle del río Chillón:

"Antes de la venida de los españoles a esta tierra estaba este valle y comarca muy poblado de indios [...]; eran dos las naciones que lo habitaban, con lenguas distintas, las cuales aún conservan hoy 
los pocos que quedan de ambas. Los naturales de Caraguayllo y sus términos eran de la una nación, cuya lengua corre desde allí adelanta por el corregimiento de Chancay y banda del septentrión; y desde el mismo pueblo de Caraguayllo hasta el de Pachacamac habitaba la otra nación.”

Rivet basaba la veracidad de este fragmento en el límite que la Historia Anónima de 1604 otorga al alcance político que tuvieron los chimos, el cual habría llegado, según esta fuente, hasta Carabayllo. Sea como fuere, el deseo de delimitar las áreas lingüísticas llevó a Torero (1986: 541) a recurrir al fonetismo de las lenguas para establecer áreas toponímicas. A nivel fonético, este autor postuló la total ausencia de w y la abundante presencia de f y rr en Lambayeque. ${ }^{7}$ A nivel morfológico, afirmaba que abundaban en Lambayeque los topónimos terminados en - nique, que de acuerdo con este autor correspondía a la palabra 'río'. Asimismo, refería que en la zona de Trujillo abundaban los antropónimos acabados en-namo que, según De la Calancha ([1639] 1977: 1227), significaría 'padre':

"Llamaron a este Capitán (que después de la Vitoria nonbró por Gobernador el Chimo) Pacatnamu, que en aquella lengua quiere decir padre común, o padre de todos, porque onrando a los vencedores, acariciava a los vencidos, a su adulación se llamó el valle de Pacatnamu, i oy se llama corrupto el nonbre el valle de Pacasmayo; i el cerro donde fundó su casa, cuyas reliquias viven, conserva sin corrupción el nonbre de Pacatnamu (...)"

La delimitación de áreas toponímicas sobre la base de algunos sonidos o morfemas empleados, en un caso, en Lambayeque y, en otro, en Trujillo da una idea de que el mochica y la lengua quingnam o pescadora habrían sido entidades, absolutamente, discretas. Hasta aquí llegaría el conocimiento actual de la lengua pescadora. Afortunadamente, las nuevas informaciones que daremos a conocer permitirán tener una idea más documentada de la lengua en cuestión.

$7 \quad$ Antes que Torero, Rabinowitz (1983: 261) había elucubrado algunas características que podría haber tenido la lengua pescadora, pero sin mayor apoyo empírico.

Bol. Acad. peru. leng. 50(50), 2010 


\section{Nuevas informaciones}

Las nuevas informaciones que podemos presentar acerca de la lengua pescadora se deben a la publicación de textos antiguos. Esta sección consta de tres subsecciones. En la primera, los elementos para delimitar áreas lingüísticas como entidades discretas serán revisados a la luz de nuevos hallazgos, los cuales dan una idea de bilingüismo en la sociedad Chimú. La segunda subsección nace de la publicación de la Crónica de Ocxaguaman. Zevallos Quiñones publicó, en 1994, la Crónica de Ocxaguaman, la cual es un conjunto de documentos judiciales que van de 1562 a 1565 y que permiten hacer inferencias sobre la distribución de la pescadora. De igual modo, una nueva reedición motiva la tercera subsección de esta segunda parte. El año 2006, con ocasión de cuarto centenario de Santo Toribio de Mogrovejo, José Antonio Benito editó en su integridad el Libro de visitas del arzobispo limeño, en donde aparecen datos explícitos sobre la lengua pescadora, los cuales permanecían inéditos. La edición de estas fuentes permite ampliar nuestro conocimiento de la lengua pescadora, tanto por los datos que aportan, como por la reinterpretación que debemos hacer de lo ya conocido.

\subsection{Situación de bilingüismo}

El reconocimiento del bilingüismo en una franja que va de Pacasmayo a Chicama se logra por las informaciones explícitas del cronista De la Calancha, en donde manifiesta que Jequetepeque y San Pedro de Lloc hablaban mochica quingnam. Este hecho se confirmaría, a su vez, a través del cruce de información de la crónica de Antonio De la Calancha con el documento Ramos y el Arte de Fernando de la Carrera, constatándose así una situación de bilingüismo para los valles de Jequetepeque y Chicama. La Historia Anónima de 1604 (Vargas Ugarte 1936: 231) relata, precisamente, la temprana conquista de "Chicama hasta Pacasmayo", por el ya mencionado Nañcen Pinco. Estas zonas de habla mochica habrían consentido en hablar la lengua de los chimúes que, según estimamos, era la quingnam o pescadora. Todas estas informaciones corresponden al siglo XVII. Los datos del siglo XVI, empero, permitirán extender el bilingüismo más allá de Chicama. 
Con todo, la manera tajante como los morfemas -nique (en topónimos de Lambayeque) y -namo (en antropónimos de Trujillo) separan las entidades lingüísticas no permite apreciar el bilingüismo chimú en su real dimensión. Este análisis no solo se resiente por falta de apoyo empírico, sino que tiene errores léxicos. Por nuestra parte, más bien creemos que la desinencia -nique es la forma castellanizada del morfema locativo -nic (Carrera 1644: 120), pues muchos topónimos acabados en tal desinencia -nique carecen de un entorno fluvial que justifique el uso de tal terminación con el significado de 'río', además es preciso apuntar que la forma -nique no corresponde con la del término mochica nech 'río'(Carrera 1644: 2).

Ahora bien, la división tajante de segmento /f/ para Lambayeque y no para Trujillo y la exclusividad de la terminación -namo en nombres trujillanos, como algo ajeno a la consonante en cuestión, no soportan un análisis en profundidad. En un documento de 1565, publicado por Ramírez (1995: 250), los nombres de los señores con la desinencia -namo son Chancachinamo, Lillonamo, Mynchonamo, Chachaynamo y Chonlonamo. Mas, junto a estos nombres, se presentan otros que son, típicamente, mochicas por la presencia de /f/, como Fayese o Yfsacanamo, que posee el segmento /f/, propio del mochica y la terminación -namo, propia de los nombres chimúes. De cualquier forma, los nombres mixtos son comunes en la antroponimia andina. Tan es así que Zevallos Quiñones (1993) nos presenta, nuevamente, antropónimos que portaban el segmento /f/ y finalizaban con la ya mentada desinencia -namo. En pleno valle de Chimo, hacia 1561, Zevallos Quiñones (1993: 48) presenta el nombre de Llufucnamo, que designaba a un indio propietario de tierras en dicho valle y, a su vez, menciona el nombre Efan Paspanamo para el valle de Chicama, en 1604 (Zevallos Quiñones 1993: 36). De igual modo, el mismo autor da a conocer los nombres Cafo en Mansiche, Chancaf en Huanchaco y Mansiche, Choyfuc o Choyfoc en Mansiche, Ferru en Trujillo, Fillñun en Mansiche, Llifin en Mansiche, Nefuc en Trujillo, Niunfir en Moche, y Poc poc, que era el nombre de un ave agorera en mochica para el pueblo de Mansiche. Esto nos hace cuestionar la división tajante, en favor del bilingüismo de la zona. En el apéndice II del articulo de Ramírez (1995: 278-279) se da una lista de las autoridades de Chicama, donde la desinencia -namo o -namu se multiplica copiosamente: 
Soquenamo $\sim$ Sequenamo, Quispipnamo $\sim$ Quilpinamo $\sim$ Quilpipnamo, Chumbinamo, Chayan nam $\sim$ Chayan namu, Suchinamo, Am nop namo, Yspac namo, Sulpinamu, Nynconamu, Chanytnamo, Sornamo, Conamanu, Ancoynamo, Guamannamo, Savaynamo. Pero en este listado también nos percatamos de nombres mochicas, tales como Nocfe, Fayo, Payquef o Quenarrefe, lo cual refuerza la hipótesis del bilingüismo trujillano, hasta mediados del siglo XVI.

Así, los antropónimos denotan, claramente, que en el valle de Chicama se hablaba tanto el mochica como la lengua de los chimúes que conocemos como quingnam o pescadora. Es probable que ésta sea la lengua que hablaron los negros cimarrones que frecuentaban los pueblos de la mar, en dicho valle. Siguiendo un testimonio de 1565, Castañeda (2004: 130) escribe: “(...) los negros participaban en las fiestas que hacían los indios y además hablaban la lengua yunga." Del mismo modo, la antroponimia proporciona indicios de un bilingüismo más al sur de Chicama.

Rostworowski (1992: 12-15) también planteó el segmento /f/ como elemento de diagnóstico de nombres yungas en las serranías de Cajamarca. Así, en las visitas a Cajamarca de 1571, podemos observar, a su turno, antropónimos típicamente mochicas en el pueblo de San Joseph de Chanchan (Rostworowski [1571] 1992: 255263), verbigracia: Chequinaf, Chozfui, Eltefel, Esfuyo, Estefe, Estefel, Estefo, Ezquen, Farquete, Fasique, Felchon, Fellen, Fequen, Feychen, Funchon, Funchun, Lleuchun, Quesquen, Sop, Xufil, Zonfe, Zonfel y, curiosamente, Chimo; por mencionar tan sólo aquellos que evidencian la fisonomía mochica de manera transparente. Ahora bien, como Chanchán se encuentra a las afueras de Trujillo, pensamos que esos nombres corresponden a antiguos habitantes de dicha urbe. La presencia del apellido Chimo refuerza esta hipótesis. Este último resulta un caso paradigmático del bilingüismo trujillano, pues Pedro Chimo, a todas luces natural de Trujillo, se encontraba casado con Costança Chosfui, quien a no dudarlo tenía un apellido plenamente mochica. 
Todas las fuentes tardías del siglo XVII, excluyen Trujillo como localidad de habla mochica. Las fuentes del siglo XVI empero, nos hablan de bilingüismo, incluso en el valle de Moche. Gonzalo Fernández de Oviedo (1855: 224-225) escribe:

"En otras ochenta ó noventa leguas que hay desde aqueste rio hasta la villa de Truxillo hay otras lenguas que llaman mochicas, é las mugeres que visten como las de Tumbez, é los indios camisetas é pánicos y en las cabeças unas madexas de lana hilada colorada é muy fina, una vuelta desde á la cabeça y echado su barbiquexo: é traen todos unas mantas por capas, porque tienen por afrenta andar sin ellas, é los señores se sirven de mucho arte. Tienen sus pages é sus offiçiales é coçineros, todos hombres, no mugeres: andan en hamacas: si no es en la lengua, en todo lo demás, en trage, en serviçio, en sacrifiçios é çeremonias todos acuerdan en una cosa."

Nótese que la información temprana de Fernández de Oviedo nos permite saber que el mochica se hablaba hasta Trujillo, contraviniendo así informaciones posteriores que son el producto de la modificación del alcance de dicha lengua. Ahora bien, ¿cómo saber si las lenguas mochicas de Fernández de Oviedo corresponden a la misma lengua descrita en 1644 por Fernando de la Carrera? Fernández de Oviedo da un indicio de que estaríamos ante la misma entidad lingüística, cuando escribe (1851: 448): "En la tierra llana llaman á este animal col, é en la sierra le dicen llama (...)”. A no dudarlo, el término $\mathrm{col}$ es claramente mochica (Carrera 1644: 4). He aquí un mapa del área que Fernández de Oviedo señala como mochica: 


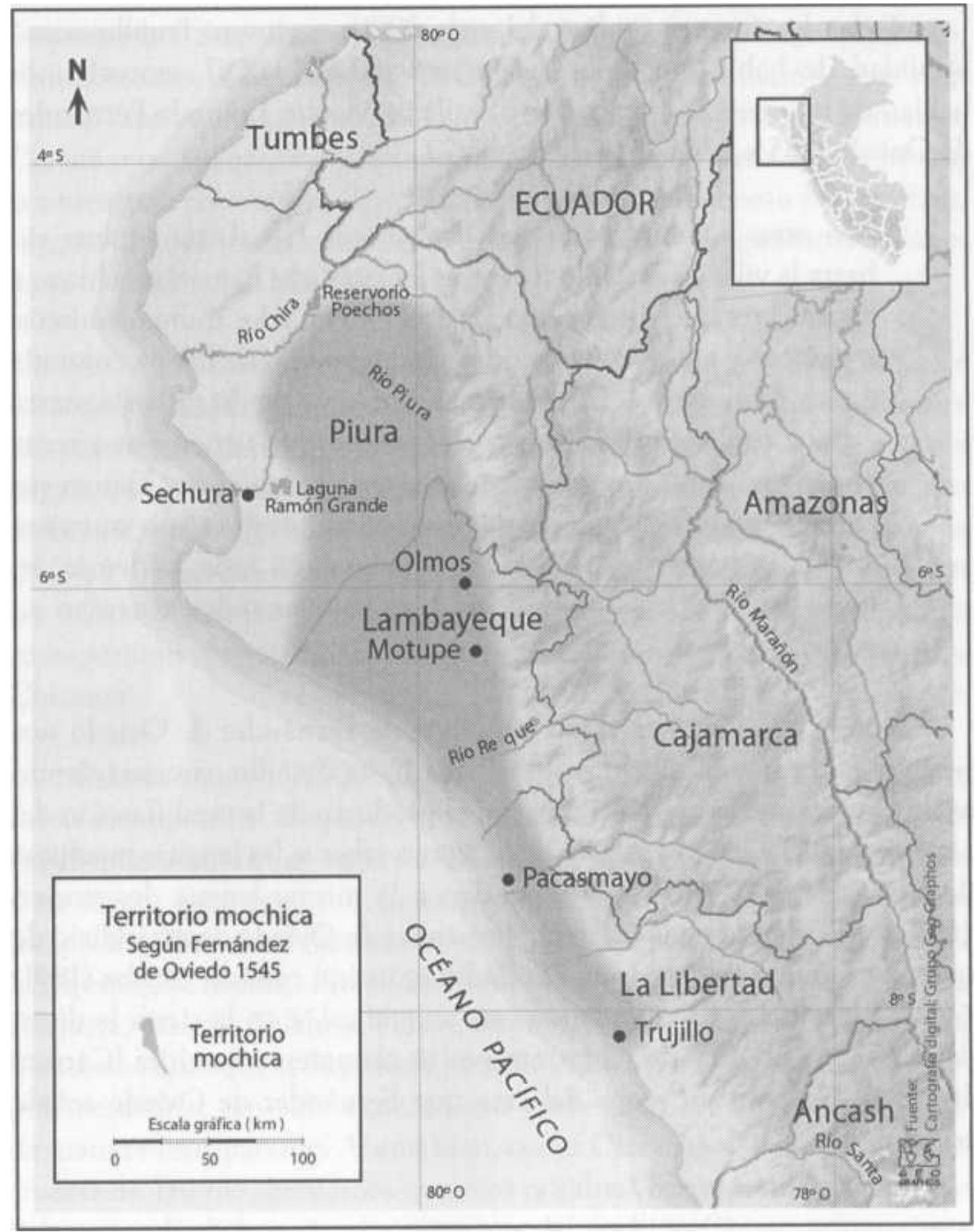

Del mismo modo, en la Relación anónima de costumbres antiguas de los naturales del Perú (1594: 169) se habla de las autoridades religiosas prehispánicas y se menciona que en cada localidad importante existía un prelado, detallando que se requería para "los Muchicas, otro, cuyo asiento era la huaca grande que está en Trujillo, que los naturales llaman 
Chimo". Cabello Valboa ([1586] 1951: 329) también aporta un indicio del bilingüismo en Trujillo. En los nombres de la segunda dinastía de gobernantes de Lambayeque se puede constatar una pista más. Obsérvese, a tal efecto, el nombre del primer gobernante de la segunda dinastía chimú de Lambayeque. Nos referimos a Pong Massa, natural de Chimo. Este personaje impuesto por el Chimo Cápac en Lambayeque tiene un nombre indudablemente mochica. La palabra pong en dicha lengua significa 'piedra' (Carrera 1644: 144) y massa significa 'guanábana' o 'chirimoya' (Brüning [1905-1924] 2004: 32). El nombre Pong Massa significa, pues, 'guanábana o chirimoya de piedra'. Se nos dice, además, de modo explícito que este personaje era procedente del Chimo, esto es, del actual Trujillo. Por ese motivo, somos de la opinión de que en Trujillo existía una situación de bilingüismo, conforme lo demuestran los documentos que venimos presentando.

Esta situación de bilingüismo para la zona del valle de Moche se ve reforzada por la Historia Anónima de 1604 que publicara Vargas Ligarte. Al ser el quingnam la lengua del Chimo, entonces, Taycanamo, fundador de la dinastía Chimú, era hablante de esta lengua. En efecto, la leyenda (Vargas Ugarte [1604] 1936: 231) relata que "de la comunicación que tubo con... yndios que los fue sujetando deprendió la lengua". Eso quiere decir que Taycanamo aprendió una segunda lengua hablada en Chimor. Por los nombres de Taycanamo y sus descendientes sabemos que no eran hablantes maternos de mochica, pues sus nombres no se parecen a los de Lambayeque. La primera posibilidad es que haya aprendido el quingnam en Trujillo y que olvidara su lengua materna, la cual nos es desconocida. Esta hipótesis, aunque probable, carece de apoyo documental. Es más, al hablar de los chimos, el propio De la Calancha se apura en decir que su lengua "era la Quingnam propria deste Reyezuelo". La segunda posibilidad es que, en efecto, Taycanamo fuese hablante de quingnam, pero aprendió como segunda lengua el idioma hablado, a la sazón, en Trujillo, que por informaciones históricas era el mochica y se valió de dicha lengua para las conquistas iniciales.

Tenemos, pues, indicios razonables para pensar en una situación de bilingüismo, la cual fue incluso más extensa en el siglo XVI, que 
en el XVII. Cronistas tempranos como Gonzalo Fernández de Oviedo ([ 1535-1557] 1855) y el Jesuita anónimo (1594) mencionan la existencia de mochicas hasta Trujillo. La Historia Anónima de 1604 (Vargas Ugarte: 1936) nos hace reflexionar sobre la lengua de los chimos y del aprendizaje que realizaron en territorio ajeno. Cabello Valboa ([1586] 1951) proporciona nombres de jefes nacidos en Trujillo de claro origen mochica. A su turno, la edición de antropónimos, correspondientes al siglo XVI, hecha en sendos trabajos por Rostworowski (1992), Zevallos Quiñones (1993) y Ramírez (1995) muestra nombres con f en Trujillo y que incluso esta consonante de origen lambayecano está en nombres trujillanos, lo cual nos hace pensar en un bilingüismo común. Esto, sin embargo, no puede ser apreciado en su real dimensión si solamente se cuenta con documentos del siglo XVII.

\subsection{Crónica de Ocxaguaman}

La Crónica de Ocxaguaman es un conjunto de documentos judiciales que van de 1562 a 1565. Lleva por nombre "crónica", porque su editor Jorge Zevallos Quiñones (1994) consideró que las noticias que aportaba eran tan novedosas y trascendentales, como las de dichas fuentes. Creemos que su decisión fue, absolutamente, acertada. La Crónica de Ocxaguaman ayuda a completar la historia de Chimor. En detrimento de su enorme importancia, ha pasado casi desapercibida para la historiografía peruana. Una manera documentada de saber dónde se hablaba la lengua de los chimos es conociendo la procedencia de los intérpretes de sus procesos contenciosos. La Crónica de Ocxaguaman da los elementos necesarios para establecer algunos juicios acerca de la lengua quingnam o pescadora.

En el proceso se echó mano de cinco intérpretes de distintas procedencias. El primero de ellos fue Cristóbal, indio alguacil natural de Casma. Este intérprete brindó traducciones para los naturales de Chimo: Felipe y Francisco Chumbinamo, Melchior Tintomy, Diego López, Juan Guamán, Alonso Chancor, Santiago Pañira, Francisco Guamán; asimismo para Felipe Guansur, natural de Huanchaco; y para un indio de Chao llamado Diego, el cual reconoció llamarse Antaro en su lengua. El que 
alguien de Casma pudiese traducir a gente de Huanchaco, Chimo y Chao es un indicio de que todos estos pueblos compartían la misma lengua. Las informaciones de la cuarta visita pastoral de Mogrovejo, que en breve presentaremos, confirman que Chao hablaba la lengua pescadora, al igual que la zona de Chimo y Huanchaco, como se afirma en el documento Ramos.

El caso del testimonio de Gonzalo Colque Chicon es interesante, pues este testigo era un "yndio biejo y prenzipal de la provincia de caxamalca y contador y quipo camayo mayor de la dha probincia”. En Cajamarca se hablaba la lengua quechua. Por eso, sus palabras fueron interpretadas "por la lengua de juan asmate e alo. yndios ladinos quel dho Juan es natural deste balle y el dho alo. natural de chicama y del prenzipal pedro mache los quales juraron por Dios e por santa ma. en forma de dro de ynterpretar verdad (...)". Ahora, como Colque Chicon era quechuahablante hubo la necesidad de recurrir al principal Pedro Mache, que únicamente para este caso efectúa una traducción. Recuérdese que los nobles de las provincias sojuzgadas por los incas tuvieron el imperativo de aprender el quechua. Juan Asmate de Chimo y Alonso de Chicama, por su parte, tradujeron además a Xarcanamo, Simanamo, Felipe y Francisco Chumbinamo, Gonzalo Auyer Quejo, Juan Guamán, Melchior Tintomy, Cristóbal Yaycheque, Alonso Cachay y a los indios Diego y Antonio. Todos estos testigos, aparentemente, procedían de Chimo. Lo interesante es que los intérpretes Alonso y Juan Asmate, naturales de Chicama y Chimo respectivamente, interpretaron a Melchior Tintomy, Juan Guamán, Felipe y Francisco Chumbinamo, quienes a su turno pudieron ser traducidos por el intérprete Cristóbal de Casma. Así, tenemos que Chicama, Huanchaco, Chimo, Chao y Casma poseían una lengua, mutuamente, inteligible. En el documento Ramos, además de los ya mentados Chimo y Huanchaco, se cita pueblos ubicados en el valle de Chicama, como hablantes de la pescadora, mientras que la nueva edición del texto completo de Mogrovejo menciona tanto a Chao, cuanto a Casma, como pueblos de habla pescadora.

Hasta aquí hemos mencionado a cuatro intérpretes. El quinto es Cristóbal Gutiérrez, yanacona alguacil, natural de Huaura. Cristóbal 
Gutiérrez traduce lo dicho por "Don pedro cacique deste balle y a don Myn. que ha sido su governador y a don Gonzalo principal y don Felipe principal de guanchaco y a don diego guarnan y don Hernando sepnamo e otros principales (...)". Asimismo, Gutiérrez hizo entender un mensaje del rey de España a los principales del valle de Chimo: Francisco Chumbinamo, Diego López, Diego Guamán Cache, Francisco Guamán Payco, don Hernando, don Felipe, don Juan, y don Diego, hijo bastardo de Antonio Chayguaca. No sorprende que alguien de Huaura hablase la misma lengua de los chimos, pues, según la Historia Anónima de 1604 publicada por Vargas Ugarte (1936: 232), Chumun Caur, hijo de Minchan Çaman, era precisamente de dicho pueblo. Nótese de paso que Cristóbal Gutiérrez traduce y trasmite mensajes para algunos de los que fueron interpretados por los otros traductores, lo cual comprueba que Chicama, Huanchaco, Chimo, Chao, Casma y Huaura poseían una lengua común. La distribución de tal lengua se inscribe dentro de las fronteras del territorio bajo control Chimú en el siglo XVI.

\subsection{Libro de visitas de Mogrovejo}

La edición completa del Libro de visitas de Mogrovejo, además de la segunda, trae los pormenores de la tercera y cuarta visita pastoral del arzobispo limeño. Cuando se habla del pueblo de Chao reducido en Guañape, se informa que "no sabe el dicho cura la lengua pescadora que es la materna de estos indios ni tampoco la general del inca que algunos de ellos hablan" (Mogrovejo [1605] 2006: 443). En la segunda visita pastoral se decía que en el pueblo de Guañape el sacerdote "sabe la lengua", pero sin mencionar cuál. Más al sur, para la villa de Santa, "no saben los curas la lengua pescadora. Ninguno de los curas sabe la lengua pescadora" (Mogrovejo [1605] 2006: 439). Continuando hacia meridión, en el pueblo de San Sebastián de Enepeña, el sacerdote "no sabe mucho la lengua pescadora. Sabe el dicho cura muy poco la lengua pescadora de estos indios, doctrínalos en la de Castilla y general que entienden los indios de esta doctrina un poco y esta lengua general sabe el dicho cura razonablemente" (Mogrovejo [1605] 2006: 434). Para los pueblos de Quisquis, Llaután y San Francisco de Parquín, "no sabe la lengua 
yunga ni serrana. No sabe el dicho cura la lengua yunga ni serrana en ninguna manera para estos indios que es la que ellos saben" (Mogrovejo [1605] 2006: 431). En este caso, la lengua serrana no puede ser otra que el quechua, mientras que la lengua yunga sería la pescadora, pues el mochica no se habló en Ancash. En la segunda visita pastoral, se leía que, en Quisquís, el cura "sabe la lengua que hablan los indios", aunque no se decía cuál era dicha lengua.

Con relación a Casma Alta y Casma Baja se decía en la segunda visita de Mogrovejo que eran pueblos yungas, pero no se hablaba de la lengua. En tal caso, el término yunga designaba más la ubicación geográfica de dichos pueblos que una entidad idiomàtica. Empero, en 1605, sí se nos proporciona información propiamente lingüística. Así, "no sabe el dicho cura la lengua yunga de los indios de Casma Alta y Baja que es la que hablan aunque algunos saben la de Castilla" (Mogrovejo [1605] 2006: 428). Nuevamente, al no ser territorios ni quechuas ni mochicas, la mentada lengua yunga no sería otra que la pescadora.

Ahora bien, un dato curioso es lo que se dice acerca del pueblo de Huarmey, pues allí se afirmaba en 1593 que el cura "sabe la lengua general y los indios hablan la yunga y entienden muy poco de la general". Hacia 1605, la realidad que se describe es muy diferente. "Sabe la lengua de los indios el cura. Sabe el dicho cura la lengua general que es la que hablan estos indios" (Mogrovejo [1605] 2006: 424). La interpretación que damos a esta información es que la evangelización en quechua empezó a sustituir la lengua pescadora, la cual no era conocida por los sacerdotes de Chao, Guañape, Santa, Nepeña, Casma, Quisquís, Llaután o San Francisco de Parquín. Creemos que para los curas resultaba más práctico aprender solamente el quechua, puesto que permitía con una misma lengua doctrinar en distintas zonas del virreinato, en vez de aprender lenguas regionales que hubieran o bien limitado su ámbito de acción, o bien supuesto un esfuerzo adicional en el aprendizaje. A fuerza de repetición, los indios de Huarmey que entendían poco la lengua general en 1593, la hablaban en 1605 , puesto que era la única que conocía su sacerdote. La obra evangelizadora hizo retroceder la pescadora hasta su total desaparición. 
La edición completa del Libro de visitas de Mogrovejo no solamente aporta datos para Ancash, sino también para la zona costera de Lima. El 24 de julio de 1593, se asevera que el cura que oficia en Pativilca "sabe poco la lengua", aunque no se menciona cuál es esa entidad idiomàtica. Hacia 1605, en Pativilca el cura "sabe la lengua general de los indios que es la que hablan y en que los doctrina" (Mogrovejo [1605] 2006: 335). El 20 de julio de 1593, no se dice qué lengua se hablaba en Barranca. Solamente se menciona que el sacerdote es "buen lengua". El 22 de febrero de 1605, en Barranca, podemos conocer que habitaban los "indios yungas que hablan la lengua general y los doctrina en ella el dicho cura" (Mogrovejo [1605] 2006: 330). En Huacho, "hablan la lengua general y son doctrinados en ella" (Mogrovejo [1605] 2006: 327) y, en Huaral, el 13 de julio de 1593 se informa, sin especificar, que el sacerdote "sabe la lengua". En contraste, en 1605, se deja saber que están "hablando estos indios la lengua general en que son doctrinados" (Mogrovejo [1605] 2006: 321). Estos datos corresponden a los primeros años del siglo XVII y, necesariamente, nos obligan a reinterpretar las informaciones brindadas por Antonio De la Calancha, la Historia Anónima de 1604 y Bernabé Cobo.

Por lo que hace a De la Calancha, hay que considerar que este autor, al describir la realidad de las conquistas de los chimos, se está refiriendo a hechos que acaecieron en el siglo XVI y no en el XVII, que es el siglo en el que este cronista escribió su obra. Así, cuando De la Calancha asevera que la lengua quingnam se habló hasta Lima, esto se debe haber producido en el tiempo de mayor auge de la cultura Chimú y no en la época que le tocó vivir. Por esta razón, el mismo De la Calancha dice que la lengua quingnam es la que hablan en el momento en que él escribe (siglo XVII) en los "valles de Trujillo", esto es, no solamente en el valle de Moche, sino en la jurisdicción de Trujillo que, a la sazón, no era la misma que el actual departamento de Trujillo; toda vez que Trujillo correspondía a un obispado que iba de Colán a Santa. De ahí que se haga referencia a los valles de Trujillo en plural.

Es preciso, pues, establecer cuáles fueron los valles de Trujillo a los que De la Calancha hace alusión y, si es el caso, determinar que otros valles además de aquél empleaban la lengua quingnam o pescadora. Por 
el norte, este autor menciona que en los tiempos de Francisco Monroy, quien fue sacerdote de 1553 a 1583, se habla en presente el muchic y el quingnam. Hasta finales del siglo XVI se usó el quingnam o pescadora en Pacasmayo. El documento Ramos de 1630 ya no menciona la zona de Pacasmayo más que como territorio mochica. Lo propio hará Fernando de la Carrera. El mismo De la Calancha decía que Pacasmayo usó el quingnam en los momentos de auge Chimú, es decir, como una segunda lengua de relación. Es probable que para cuando De la Calancha escribiera, Pacasmayo, solamente, contase con hablantes ancianos bilingües. Por ello, todas las palabras que ofrece de esta zona son, en realidad, términos provenientes del mochica, que fue la lengua que sobrevivió a la caída Chimú. A su turno, por la zona austral, la distribución de la pescadora del documento Ramos se superpone con la de Mogrovejo, que incluso la extiende en su cuarta visita pastoral por el sur de manera explícita, esto es, mencionando a la lengua pescadora como tal hasta Nepeña y por medio de inferencias que hemos hecho al interpretar el término "yunga" hasta Casma. Si consideramos lo expresado por De la Calancha, los aportes del documento Ramos y de la edición completa del Libro de visitas de Mogrovejo, la lengua pescadora se habría hablado en el siglo XVII en Jequetepeque (en franco proceso de desaparición), Chicama, Moche, Virú, Santa, Nepeña, Casma y, probablemente, Huarmey (también en trance de consunción). El caso de Huarmey es emblemático. En 1593 se decía que sus indios hablaban una lengua yunga y entendían poco de la general. En 1605 se aseveraba que eran hablantes de la general. Aquí antes que una contradicción, vemos en este hecho el germen de la desaparición de la lengua pescadora, por acción del avance del adoctrinamiento en quechua por las costas del Pacífico. Es más, incluso el sacerdote de Nepeña, más al norte de Huarmey, ya se vale hacia 1605 de la lengua general quechua y del castellano, que, a la postre, será el único idioma que se utilizará en la costa norperuana. Está documentado el desinterés por aprender la lengua pescadora. Probablemente, la tardía creación del obispado de Trujillo hacia 1611 no consiguió frenar la desidia que tenían los sacerdotes del obispado de Lima por el aprendizaje de esta lengua. Con todo, el notario Andrés de Obregón en 1631 aún da fe de sacerdotes examinados en lengua pescadora (Zevallos Quiñones 1996: 17). 
Entretanto que en el siglo XVI el uso de la lengua quingnam o pescadora se habría dado, plenamente, en la zona boreal de Jequetepeque o Pacasmayo y habría llegado por el lado austral hasta Lima, si le damos crédito a lo afirmado por De la Calancha, la Historia Anónima de 1604 y Cobo. Estas fuentes, empero, no son las únicas que establecen la frontera política de los chimos. En una relación, cuya copia más antigua data de 1608, Cristóbal Vaca de Castro era informado de la extensión de los dominios chimúes. Los sucesos descritos deben haber sido relatados a Vaca de Castro ([1608] 1921: 15) hacia 1542 por unos informantes, ciertamente, particulares, los cuales daban como límite austral la zona de Nazca:

"Los "quipocamayos", que fueron los contadores de los ingas, hicieron relación de cómo mucho antes de los ingas, en los Llanos y costa del mar, adonde al presente está fundada la ciudad de Truxillo, que antiquísimamente fue pueblo nombrado Chimo, en él tenía su habitación un gran Señor a quien llamaban Chimo Cápac, el qual fue Señor de los Llanos y costa del mar desde Caxas y La Nasca hasta más delante de Piura, aunque algunos afirman que el señorío de Chimo Cápac llegó hasta Puerto Viejo y de allí le tributaban esmeraldas y "chaquiras" de oro y plata."

Para Cabello Valboa ([1586] 1951: 317) "los Chimocapaz [...] tenían el Ymperio, y Señorio en los llanos, y arenales de el Piru desde Guarmei hasta Tumbez." Garcilaso fija el límite meridional de los chimúes, cuando nos relata que Inca Yupangui ([1609] 1960: 237):

“(...) caminó hasta el valle que llaman los indios Huaman, y los españoles la Barranca, y de allí envió los recaudos acostumbrados de paz o de guerra a un gran señor llamado Chimu, que era señor de los valles que hay pasada la Barranca, hasta la ciudad que llaman Trujillo, que los más principales son cinco, y han por nombre Parmunca, Huallmi, Santa, Huanapu y Chimu, que es donde está ahora Trujillo, todos cinco hermosísimos valles, muy fértiles y poblados de mucha gente, y el curaca principal se llamaba el poderoso Chimu, del nombre de la provincia donde tenía su corte." 
El límite señalado por Garcilaso es también establecido por De la Calancha. Historiadores tardíos como Miguel Feyjóo de Sosa proporcionan otros límites para el dominio chimú ([1763] 1984: 3):

"Este ameno Valle, nombrado CHIMU, fue Señorío de unos Regulos, que todos se titularon CHIMUS, que en nuestro Idioma corresponde à Poderoso. Corria esta dominacion desde los confines de la Provincia de Chancay, hasta el Pueblo de Tumbez por el espacio de doscientas leguas (...)"

De igual manera, Joseph Ignacio de Lequanda ([1793] 1965: 37) nos brinda un límite meridional diferente al de los anteriores autores:

"Este Príncipe que era independiente y absoluto desde Supe hasta Tumbez, en la distancia de mas de 200 leguas de la Costa, fué sojuzgado por el mayor poder del General Inca Yupanqui, hijo primogénito del Emperador Pachacutec, IX. de este Imperio, en la batalla que le presentó en el campo de Parmunca, decidida en Santa. Se hiciéron á los márgenes de su caudaloso rio las Capitulaciones, dexando á este Regulo pacífico en sus estados, sin

$8 \quad$ Los datos de Feyjóo fueron tomados del poema Lima Fundada o Conquista del Perú de 1732 escrito por Pedro de Peralta Barnuevo. En el canto segundo está la estrofa XXI que tiene la siguiente nota al pie de página: "Pachacutec fué noveno Inca, hijo de Viracocha. Envió á su hijo el principe Inca Yupanqui con su hermano Capac Yupanqui á sojuzgar al Chuquimancu que dominaba desde Runahuaná hasta Chilca, en cuyos dos lugares solos habia sesenta mil vecinos. Ressistióse este valeroso. Sitiáronlo, mudando tres veces el ejército y haciendo de los cuarteles otro Cuzco. Rindiéronlo y ejecutaron lo mismo como Cuysimancu que reinaba desde allí en otros cuatro valles en que se incluía el de Rímac o Lima, de donde pasaron á debelar al Gran Chimú que imperaba desde Chancay hasta donde hoy está Trujillo. Pero todos obtuvieron de la benignidad de Pachacutec quedar con sus estados debajo del reconocimiento á su poder. Los historiadores citados." Tales historiadores son Garcilaso, de Cieza y Gómara. De ellos sólo Garcilaso habla del chimo. Si la fuente de Pedro de Peralta Barnuevo fue Garcilaso de la Vega, entonces, la referencia a la provincia de Chancay, por parte de Feijoo, no coincide en tanto área geopolítica con la de Paramonga que se halla en otra provincia. El origen del error debe dimanar de Pedro de Peralta Barnuevo, de quien Feijoo tomó la información. Peralta debe haber tomado la referencia de Chancay de Bernabé Cobo ([1639] 1964a: 301). 
otra pensión ni omenage, que el de adorar por único Dios al sol, y repudiando para ello sus Idolos patrios á quienes daban culto en sus suntuosos adoratorios."

Aun así, pese a que las dos últimas informaciones corresponden a reconstrucciones del pasado bastante tardías en relación con los hechos, parece indudable que no hay acuerdo en señalar el límite político meridional de los chimúes. Con las informaciones arriba citadas hemos elaborado la siguiente tabla, ordenada cronológicamente, la cual detalla la fecha, el autor y el límite que establece hacia el sur:

Frontera meridional del quingnam

\begin{tabular}{|c|c|c|}
\hline Fecha & Autor & Ubicación \\
\hline 1542 & Cristobal Vaca de Castro & Nazca \\
\hline 1586 & Miguel Cabello Valboa & Huarmey \\
\hline 1604 & Historia Anónima & Carabayllo \\
\hline 1609 & Inca Garcilaso de la Vega & Paramonga \\
\hline 1639 & Antonio de la Calancha & Paramonga \\
\hline 1639 & Bernabe Cobo & Carabayllo \\
\hline 1732 & Pedro de Peralta Barnuevo Rocha y Benavides & Chancay \\
\hline 1763 & Miguel Feyjóo de Sosa & Chancay \\
\hline 1793 & Joseph Ignacio de Lequanda y Escarsaga & Supe \\
\hline
\end{tabular}

Con todos estos datos, la determinación de la lengua quingnam o pescadora hacia el sur se convierte en una cuestión que, únicamente, podrá ser dilucidada de manera empírica. Si bien hemos aportado documentos que amplían nuestro saber de esta lengua, es imperativo hallar nuevas evidencias que no solamente mencionen un límite político, sino que proporcionen información lingüística fidedigna. En ese contexto, la afirmación de Rivet de que el quingnam, según Cobo, se habló hasta Carabayllo debe tomarse como una hipótesis a ser verificada. En efecto, de acuerdo con Cobo, antes de la venida de los españoles, esto 
es, antes de 1532, había dos naciones con lenguas diferentes y que aún quedaban pocos en los tiempos que dicho sacerdote escribió su crónica. Sin embargo, Cobo jamás menciona el quingnam, como se lo atribuye Rivet. Las dos naciones con lenguas diferentes bien podrían ser variedades bastante diferenciadas de quechua. La cuarta visita pastoral de Mogrovejo hace hablar a las zonas costeras de Lima en quechua. Curiosamente, De la Calancha ([1639] 1974: 134) pone palabras quechuas en boca de los habitantes nativos de Lima:

"Los indios de Lima llaman a esta flor Cururuncui Machacaquainavi, que enla lengua general quiere decir ojo de culebra, bebida en vino sana el mal de sangre. Otra ay casi la misma, i sólo se diferencia en que es doblado mayor, i entre cinco ojas en que se funda, que tienen forma de yerro de lança, ay tres, que todas se quajan de ramales, mayores son las llagas, i la corona es de color cardeno, la oja como la de las malvas, no es yerva que trepa, sino mata pequeña, la fruta es dulce, i la comen los Indios, llámanla los lungas Potpic, i los Españoles Puchepuche, es linda flor."

Aun hoy, la palabra quechua Machacaquainavi es susceptible de análisis, pues mach 'aqway significa 'culebra' y ñawi, 'ojo'. Téngase muy presente que la glosa que ofrecía De la Calancha como traducción era: "ojo de culebra". Determinar si esos habitantes fueron hablantes de quechua desde siempre o a partir de la evangelización es también una cuestión empírica. Así, para la primera mitad del siglo XVI, en el que estaba en auge la cultura Chimú, el quingnam o pescadora se habría hablado de Pacasmayo hasta algún lugar de la región de Lima. La Crónica de Ocxaguaman que va de 1562 a 1565 permite inferir que se usó al menos hasta Huaura, lo cual está acorde con el origen de Chumun Caur, hijo de Minchan Çaman. En el siglo XVII, tal entidad lingüística se retraía de Pacasmayo en el norte y de Huarmey, por el sur, a estar por lo aseverado en el Libro de visitas de Mogrovejo. En tiempos de Cobo y De la Calancha avanzaba el quechua por la costa norte de Lima hacia el litoral de Ancash. Afirmar que Lima (como De la Calancha) y Carabayllo (como Cobo) en el siglo XVII eran territorios de la lengua quingnam o pescadora resulta erróneo. 


\section{Conclusiones}

Por lo que hace a los límites de la lengua pescadora o quingnam, hay que decir que el establecimiento de los mismos, hasta ahora, se había dado en todos los casos sobre la base de informaciones del siglo XVII, proporcionadas por el documento Ramos, De la Calancha o De la Carrera. El panorama en el siglo XVI, sin embargo, es diferente. Los datos onomásticos (topónimos y antropónimos) nos hablan de un bilingüismo de Pacasmayo a Chicama en el siglo XVII, con tendencia a la desaparición de la lengua pescadora de Pacasmayo. A su vez, la onomástica junto con las fuentes de las crónicas tempranas nos hace pensar que este bilingüismo era aun más extendido, llegando incluso hasta Trujillo en el siglo XVI. Ahora bien, una fuente de capital importancia para determinar la realidad de la costa norperuana es la Crónica de Ocxaguaman, la cual nos hace conocer que desde Huaura hasta Chicama existían intérpretes que se entendían en la misma lengua, siendo este hecho compatible con el área lingüística que habría ocupado la pescadora o quingnam en la primera mitad del siglo XVI. El distinguir la información del siglo XVI de la del XVII pone de manifiesto la diferencia de alcance del bilingüismo entre la pescadora o quingnam y el mochica, llegando incluso hasta la zona de Trujillo, lo cual no podría ser conocido, si únicamente nos valiésemos de la información del siglo XVII. Otra fuente importante de conocimiento para la lengua pescadora se encuentra en el Libro de visitas del arzobispo de Lima Toribio de Mogrovejo. En efecto, Mogrovejo ha sido una fuente que no se había podido utilizar cabalmente, debido a los vacíos que dejara la edición parcial de dicho manuscrito. La completa nueva edición subsana alguna de las lagunas anteriores y obliga a reinterpretar los datos hasta hoy conocidos. Así, es necesario acotar las informaciones para el siglo XVII, distinguiéndolas de las que se poseen para el siglo XVI. Los datos de la cuarta visita de Mogrovejo a comienzos del XVII muestran la lengua pescadora en una franca situación de retracción por la pérdida de poder de los chimos hacia el norte en Pacasmayo y la acción de la obra evangelizadora que avanzaba por el sur con la lengua quechua y el castellano. Los nuevos documentos permiten un mayor conocimiento de la lengua pescadora más allá de Virú, que era la anterior frontera de nuestro saber. 


\section{BIBLIOGRAFÍA}

ANÓNIMO. [¿1594?] 1968. Relación de las Costumbres Antiguas de los Naturales del Pirú. En Esteve Barba, Francisco (editor): Crónicas peruanas de interés indígena (= Biblioteca de Autores Españoles CCIX). Madrid: Ediciones Atlas, pp. 151-189.

BRÜNING, Hans Heinrich. [1905-1924] 2004. Mochica Wörterbuch (= Patrimonios: Lingüística II). Edición y estudio introductorio de José Antonio Salas García. Lima: USMP.

CABELlO VALBOA, Miguel. [1586] 1951. Miscelánea Antàrtica. Lima: Instituto de Etnología de la UNMSM.

CALANCHA, Antonio De la. [1639] 1974. Crónica moralizada (= Crónicas del Perú 4). Edición de Ignacio Prado Pastor. Lima: Imprenta de la UNMSM. Volumen I.

. [1639] 1976. Crónica moralizada (= Crónicas del Perú 6). Edición de Ignacio Prado Pastor. Lima: Imprenta de la UNMSM. Volumen III.

. [1639] 1977. Crónica moralizada (= Crónicas del Perú 7). Edición de Ignacio Prado Pastor. Lima: Imprenta de la UNMSM. Volumen IV.

CARRERA DAZA, Fernando de la. 1644. ARTE DE LA LENGVA YVNGA DE LOS VALLES del Obispado de Truxillo del Peru, con un Confessonario, y todas las Oraciones Christianas, traducidas en la lengua, y otras cosas. Lima: Joseph de Contreras.

CASTAÑEDA MURGA, Juan. 2004. "Los pueblos de la mar: Pasado y presente de la costa trujillana". En Valle Alvarez, Luis (ed.): Desarrollo Arqueológico de la Costa Norte del Perú (=Arqueología 2). Trujillo: Ediciones SIAN. Tomo II, pp. 129-140. 
CERRÓN-PALOMINO, Rodolfo. 1995. La lengua de Naimlap (reconstrucción y obsolescencia del mochica). Lima: Fondo Editorial de la PUCP

COBO, Bernabé . [1639] 1964a. Fundación de Lima. En Mateos, Francisco (ed.): Obras del P. Bernabé Cobo (= Biblioteca de Autores Españoles 92). Madrid: Ediciones Atlas. Tomo II

. [1653] 1964b. Historia del Nuevo Mundo. En Mateos, Francisco (ed.): Obras del P. Bernabé Cobo (= Biblioteca de Autores Españoles 92). Madrid: Ediciones Atlas. Tomo II

FERNÁNDEZ DE OVIEDO Y VALDÉS, Gonzalo. [1535-1557]. 1851-5 Historia General y Natural de las Indias, islas y tierra firme del mar océano. Madrid: Real Academia de la Historia.

FEYJÓO DE SOSA, Miguel Manuel. [1763] 1984. Relación Descriptiva de la Ciudad, y la Provincia de Truxillo del Perú, edición facsimilar. Lima: Fondo del Libro del Banco Industrial del Perú. Volumen I.

GARCILASO DE LA VEGA, Inca (= Gómez Suárez de Figueroa). [1609] 1960. Primera Parte de los Comentarios Reales de los Incas. En Saenz de Santa María, Carmelo (ed.): Obras completas del Inca Garcilaso de la Vega (=Biblioteca de Autores Españoles 133). Madrid: Ediciones Atlas. Tomo II

GUAMÁN POMA DE AYALA, Felipe. [1615] 1993. Nueva Corónica y Buen Gobierno. Lima: Fondo de Cultura Económica.

HUERTA, Alonso de. [1616] 1993. Arte de la lengua quechua general de los Yndios de este Reyno del Piru, Quito: Programa de Educación Bilingüe Intercultural.

LEQUANDA Y ESCARSAGA, Joseph Ignacio de. [1793] 1965. "Descripción geográfica de la ciudad y partido de Truxillo". 
En Sociedad Académica de Amantes de Lima (eds.): Mercurio Peruano, edición facsimilar. Lima: Biblioteca Nacional del Perú. Tomo VIII, número 247, pp. 36-43.

LIZARRAGA, Reginaldo de (= Baltasar de Ovando). [1605] 1968. Descripción breve de toda la tierra del Perú, Tucumán, Río de la Plata y Chile (= Biblioteca de Autores Españoles CCXVI). Madrid: Ediciones Atlas.

MOGROVEJO, Toribio Alfonso de. [1593] 1920. "Diario de la segunda visita pastoral que hizo de su arquidiócesis el ilustrísimo señor don Toribio Alfonso de Mogrovejo, arzobispo de los Reyes". Revista del Archivo Nacional, tomo I, entrega 1, pp. 31-81; entrega 2, pp. 227-279; entrega 3, pp. 401-419.

. [1593] 1921. "Diario de la segunda visita pastoral que hizo de su arquidiócesis el ilustrísimo señor don Toribio Alfonso de Mogrovejo, arzobispo de los Reyes". Revista del Archivo Nacional, tomo II, entrega 1, pp. 37-78.

. [1593-1605] 2006. Libro de visitas de Santo Toribio Mogrovejo. Introducción, transcripción y notas de José Antonio Benito Rodríguez. Lima: Fondo Editorial de la PUCP.

PERALTA BARNUEVO ROCHA Y BENAVIDES, Pedro de. [1732] 1863. Lima Fundada o Conquista del Perú (= Colección de Documentos Literarios del Perú I). Lima: Establecimiento de tipografía y encuadernación de Aurelio Alfaro.

RABINOWITZ, Joel. 1983. "La Lengua Pescadora: The Lost Dialect of the Chimu Fishermen." En Sandweiss, Daniel H. (ed.): Investigations of the Andean Past. Papers from the First Annual Northeast Conference on Andean Archaeology and Ethnohistory. Ithaca, New York: Cornell University, pp. 243-267. 
RAMÍREZ-HORTON, Susan Elizabeth. 1995. "De pescadores y agricultores: Una historia local de la gente del valle de Chicama antes de 1565". Bulletin de l'Institut Français d'Études Andines, tomo 24, número 2, pp. 245279.

RAMOS CABREDO, Josefina. 1951. "Las Lenguas en la Región Tallanca". Cuadernos de estudios del Instituto de Investigaciones Históricas de la Universidad Católica del Perú, tomo III, número 8, pp. 11-55.

RIVET, Paul. 1949. "Les langues de l'ancien diocèse de Trujillo". Journal de la Société des Américanistes, tomo XXXVIII, pp. 1-51.

ROSTWOROWSKI TOVAR DE DIEZ CANSECO, Maria. 1981. Recursos naturales renovables y pesca, siglos XVI y XVII (= Historia andina 8). Lima: IEP.

ROSTWOROWSKI TOVAR DE DIEZ CANSECO, María \& Pilar Remy Simatovic(eds.). [1571-72/78] 1992. Las visitas a Cajamarca 157172/1578 (= Fuentes e investigaciones para la historia del Perú 9). Lima: IEP. Tomo I.

SAN PEDRO, Juan de \& Juan del Canto. [1560] 1992. Relación de los agustinos de Huamachuco (= Relación de la religión y ritos del Perú hecha por los padres agustinos). Estudio preliminar de Lucila Castro de Trelles. Lima: Fondo Editorial de la PUCP.

SANTO TOMÁS, Domingo de. [1560] 1951.Lexicón o vocabulario de la lengua general del Perv, edición facsimilar con prólogo de Raúl Porras Barrenechea. Lima: Edición de Instituto de Historia de la UNMSM.

TORERO FERNÁNDEZ DE CÓRDOVA, Alfredo. 1986. "Deslindes lingüísticos en la costa norte peruana”. Revista Andina, 8, pp. 523 - 548. 
1989 “Áreas toponímicas e idiomas en la sierra norte peruana. Un trabajo de recuperación lingüística". Revista Andina, 13, pp. 217 - 257.

VACA DE CASTRO, Cristóbal. [1608] 1921. "Discurso de la descendencia y gobierno de los Incas." (= "Declaración de los quipocamayos a Vaca de Castro"). En Urteaga, Horacio (ed.): Informaciones sobre el antiguo Perú (= Colección de libros y documentos referentes a la historia del Perú, tomo III, 2a serie). Imprenta y librería San Marti y Cía. pp. 1-53.

VARGAS UGARTE, Rubén. 1936. "La fecha de la fundación de Trujillo". Revista Histórica (= Órgano del Instituto Histórico del Perú), tomo X, entrega II, pp. 229-239.

ZEVALLOS QUIÑONES, Jorge. 1948. "Los gramáticos de la lengua yunga". Cuadernos de Estudios del Instituto de Investigaciones Históricas de la Universidad Católica del Perú, tomo III, número 6, pp. 40-67.

. [1948] 2003 “Los gramáticos de la lengua yunga - 1948”. Revista del Museo de Arqueología, Antropología e Historia de la Universidad Nacional de Trujillo, número 8, pp. 349-376.

- 1993 Onomástica Chimú (= Fuentes de estudio de la lengua Quingnam: II). Trujillo: Fundación “Alfredo Pinillos Goicochea”.

1994 La crónica de Ocxaguaman (= Publicación N ³).Trujillo: Fundación "Alfredo Pinillos Goicochea".

1996 “Exámenes cúrales de las lenguas yungas en el siglo XVII”. Boletín de la Academia Peruana de la Lengua (= BAPL), número 26, pp. 9-21. 


\section{Correspondencia:}

José Antonio Salas García

Correo electrónico: jos778@ hotmail.com 